\title{
WICS: A Model of Positive Educational Leadership Comprising Wisdom, Intelligence, and Creativity Synthesized
}

\author{
Robert J. Sternberg ${ }^{1,2}$
}

Who are the people who become positive educational leaders? This essay presents WICS as a model of positive educational leadership. WICS stands for wisdom, intelligence, creativity, synthesized. Each of these elements is asserted to constitute one of the elements of educational leadership. Regrettably, our society is organized around a closed system of selection and talent development that emphasizes intelligence in a narrowly defined way that sometimes ignores its synthesis with creativity and wisdom.

KEY WORDS: leadership; WICS; wisdom; intelligence; creativity.

In this article, I propose a model, WICS, standing for wisdom, intelligence, and creativity, synthesized. I argue that educational leaders exhibit a synthesis of the three attributes of wisdom, intelligence, and creativity. To a large extent, I argue, the development and display of these attributes is a decision over which one has substantial control, not merely some kind of innate set of predispositions. I also present a sampling of the evidence my colleagues and I have collected to date in support of the model and its various aspects. I also compare WICS with other models of leadership.

The WICS model can be applied to various kinds of leadership. But my concern in this article is primarily with educational leadership and how WICS can be applied to enhance it. Hence, the examples are, for the most part, educational ones.

${ }^{1}$ PACE Center, Yale University, New Haven, Connecticut.

${ }^{2}$ Correspondence should be addressed to Robert J. Sternberg, PACE Center, Yale University, Box 208358, New Haven, Connecticut 06520-8358. 
There are many models of leadership, of course (see reviews in Antonakis et al., 2004a,b). Some are examined below.

\section{PREVIOUS MODELS OF LEADERSHIP THAT CAN BE APPLIED TO EDUCATIONAL SETTINGS}

Antonakis et al. (2004a) have identified several different schools of leadership, providing a taxonomy similar to taxonomies provided by others (see Antonakis et al., 2004b; Goethals et al., 2004). Here, I discuss different leadership approaches and some of the problems associated with each. This analysis recognizes that all leadership approaches have associated problems. There is no one perfect approach to leadership that is devoid of problematic aspects. Leadership is a complex interlocking of many antecedent skills, attitudes, and situational variables (Hunt, 2004).

\section{The Trait-based Approach}

A traditional approach is the trait-based approach (Zaccaro et al., 2004). The trait approach was particularly popular in the middle of the twentieth century when scholars attempted to identify traits associated with effective leadership (e.g., Bird, 1940; Stogdill, 1948). Stogdill (1948) suggested a number of traits associated with leadership, including intelligence, scholarship, dependability in exercising responsibility, activity and social participation, and higher socioeconomic status. The effective school principal, for example, would be someone who is smart, dependable, and gets along with other people. Mann (1959) also proposed a list of traits, including intelligence, good adjustment, extroversion, dominance, masculinity, and interpersonal sensitivity. He found conservatism to be negatively related to successful leadership. Many educational leaders are selected because they can be counted on not to rock the boat. According to Mann, they would not be among the more effective educational leaders.

There seems to be a moderate correlation between intelligence and leadership effectiveness (Stogdill, 1948; see also Morrow and Stern, 1990; Spreitzer et al., 1997; essays in Riggio et al., 2002). This positive correlation appears both in laboratory and field studies, and appears to be robust (Zaccaro et al., 2004). Certain aspects and kinds of intelligence also show positive correlations with leadership effectiveness. For example, divergent thinking is positively correlated with leadership success (Baehr, 1992; Mumford and Connelly, 1991; Mumford et al., 2002). Emotional intelligence is also a positive predictor of leadership (Caruso et al., 2002; Goleman et al., 2002; Sosik and Megerian, 1999; see also Zaccaro et al., 2004). Practical 
intelligence also predicts leadership success (Hedlund et al., 2003). An effective superintendent, say, would be able to come up with new ideas for the school system, be able to understand how people would respond to these ideas, and have practical ideas about how to implement the ideas.

More generally, Zaccaro et al. (2004) have proposed a model of attributes of leaders. The model comprises three distal attributes: personality, cognitive abilities, and motives and values, all three of which are viewed as overlapping with each other. The model also involves three proximal attributes: social-appraisal skills, problem-solving skills, and expertise/tacit knowledge. The last attribute points out, as we have (Sternberg et al., 2000), that an important part of leadership is understanding the system one is to lead. Superintendents frequently move from one job to the next at a fairly rapid clip. One thing they must keep in mind, if they wish to succeed, is the necessity of understanding the culture of the new system in which they are working before trying to implement serious changes. Otherwise, they risk failing for lack of understanding of the cultural environment in which they are working. What is "smart" in leadership, as in other things, depends on one's cultural context (Sternberg, 2004a).

There are at least three general problems with the trait-based approach. First, correlations of traits with leadership tend to be modest to moderate and hence can account for only a part, and generally, a fairly small part of what makes a leader successful. Second, the trait approach undervalues the importance of modifiability. Leaders are at least as much made as they are born. Leadership skills are teachable, and hence people can develop their leadership effectiveness in ways that trait theory cannot fully account for. Third, the trait approach is static, whereas leadership is dynamic. So this approach can account for part of what makes for a good leader, but certainly not all of it.

\section{The Behavioral Approach}

The behavioral approach fits into the tradition of B. F. Skinner and his behaviorist progenitors. Skinner, a radical behaviorist, believed that virtually all forms of human behavior, not just learning, could be explained by behavior emitted in reaction to the environment. Skinner rejected mental mechanisms. He believed instead that operant conditioning-involving the strengthening or weakening of behavior, contingent on the presence or absence of reinforcement (rewards) or punishments-could explain all forms of human behavior. Skinner applied his experimental analysis of behavior to many psychological phenomena, such as learning, language acquisition, and problem solving. Largely because of Skinner's towering presence, behaviorism dominated the discipline of psychology for several decades. 
Behavioral theories are associated with mid-twentieth-century approaches at the University of Michigan and Ohio State University. Most behaviorally oriented theorists of leadership were not as extreme as Skinner. Nevertheless, they believed that the main shortcoming of trait theories was that they dealt with alleged antecedents to leadership behavior rather than with the behavior itself Bales (1951).

A typical view was that leadership involved two kinds of behaviors: those that were mission oriented and that led to productivity and those that were person oriented and that were sensitive to people's feelings. Leaders could be either high or low in initiating structure and in showing consideration (see, e.g., Blake and Mouton, 1964; Hersey and Blanchard, 1969; Stogdill and Coons, 1957). A related view was proposed by McGregor (1960). He suggested two "theories" of leadership, which he referred to as $\mathrm{X}$ and $\mathrm{Y}$. Theory $\mathrm{X}$ assumes that people inherently dislike work and that nothing will much change that fact. Hence, leaders must act task and production oriented because otherwise employees will take advantage of them and work as little as possible. Theory $\mathrm{Y}$ assumes that people can enjoy work and feel affirmed by work if they are treated well. Hence, this theory emphasizes good treatment of employees by showing trust and respect for them and their work. According to this theory, for example, principals might treat their teachers as people committed to the caring of children. Or they might treat the teachers as people there just to collect a salary, as more loyal to their union than to their school, and as looking to goof off at the first available moment. The problem with the second (Theory $\mathrm{X}$ ) view is that treating people that way may lead them to act that way, creating a self-fulfilling prophecy.

For example, Lewin et al. (1939) and Lewin and Lippitt (1938), studying Boy Scout and other groups, distinguished three kinds of leadership styles: authoritarian, democratic, and laissez-faire. Authoritarian leaders were directive and their subordinates were productive, but generally, only so long as the leaders were in the room or otherwise keeping close watch. Democratic leaders were the most successful leaders overall. They empowered their followers. Laissez-faire leaders were as nondirective as possible, much of the time leaving it to the followers to figure out what to do. When the followers could not figure out what to do, the groups became ineffectual.

Whereas the trait approach to leadership is still somewhat active, the behavioral approach has lost much of its appeal. Indeed, a recent encyclopedia of leadership (Goethals et al., 2004) devotes less space to this approach than to any of the major "competitors." There are several reasons why the behavioral approach has lost some of its popularity. First, whereas the trait approach assumes that leadership capabilities inhere largely in predispositions to behavior, the behavioral approach assumes that they inhere largely 
in the behavior itself. Each approach is incomplete without the other. Second, the behavioral approach is really a hybrid rather than a true behavioral approach. Skinner would not have likely identified the so-called behavioral approach as truly "behavioral" because it talks about internal dispositions. Third, and perhaps most importantly, the behavioral approach is simplistic, assuming that good leadership is a function of behavior rather than behavior in context. For example, there may be some situations in which behavior based on Theory X applies better, such as those in which the work to be done is aversive and personally unfulfilling, whereas there may be other situations in which behavior based on Theory Y applies better, such as those in which the work is personally fulfilling. Should a leader raise salaries, increase work-production quotas, or redesign jobs? Probably it depends on the situation. There is no one behavior or set of behaviors that is optimal for every situation.

\section{Situational Approaches to Leadership}

Social psychology tends to emphasize the importance of situational variables in behavior. For example, two of the most famous studies of all time (Milgram, 1974; Zimbardo, 1972) are famous precisely because they show the power of situations, in the case of Milgram, in inciting obedience, and in the case of Zimbardo, in inciting guard-like or prisoner-like behavior in a prison simulation. Situational approaches to leadership similarly emphasize the importance of situations in leadership (Ayman, 2004).

The situational view is reflected in the philosophy of Leo Tolstoy (1994), who said in War and Peace: "In historical events great men-socalled-are but labels serving to give a name to the event, and like labels they have the least possible connection with the event itself. Every action of theirs, that seems to them an act of their own free will, is in an historical sense not free at all, but in bondage to the whole course of previous history, and predestined from all eternity." On this theory, good principals, for example, are good largely because they had the good fortune to be given the job and were in the right place at the right time.

Research has given some support to the situational view. For example, Leavitt (1951) examined the relative effectiveness of four kinds of communication patterns in a group situation: a chain, a wheel, a Y, and a circle. $\mathrm{He}$ found that the person in the central junction of the $\mathrm{Y}$ was most likely to be identified as a leader because that person largely controlled communication in the group, merely by virtue of his position. In contrast, in a circle arrangement, each member of the group had a more nearly equal chance of being designated as a leader because no one controlled communication. Thus, the 
situation rather than any particular trait or behavior seemed to control who was viewed as a leader. In other studies, people seated at the head of a table were more likely to end up in a position of leadership (Howells and Becker, 1962). In a related study, Shartle (1951) reported that the best predictor of a manager's behavior was not his or her characteristics, but those of his or her boss. Thus, the leader merely mirrored the norms that the situation demanded.

The situational view is generally viewed today as oversimplified. First, whereas it rightfully acknowledges the importance of situations, it fails to acknowledge the importance of individual differences. Some leaders, in a given situation, fail, and hence are replaced, often by people who succeed better. For example, Steve Jobs took over the ailing Apple Computer Corporation from Gil Amelio, as Lou Gerstner took over the diminishing IBM corporation from John Akers. The successors saved their companies from further decline, showing that individuals matter, not just situations. Second, the situational approach fails to recognize the interaction between persons and situations. A given situation may work for one person and not for another. For example, Amelio or Akers might well have been more successful in another time. But the times did not fit their skills. "Comebacks" of formerly successful CEOs may or may not work, depending on whether the circumstances of the organization still call for the talents the CEO has to bring to the situation. Superintendents often are fired, and their successors find the success that they lacked. These successors are usually able to find the right blend of adaptation and shaping of the environment that enables them to bring in some kind of a vision, but that does not offend those who may not share this vision. Finally, the evidence in favor of the situational approach is rather minimal. There is no question that situations matter. But no data show situational variables to be exclusively important or even, perhaps, of primary importance.

\section{Contingency Approaches to Leadership}

Contingency models of leadership assume that there is an interaction between a leader's traits and the situation in which he or she finds him or herself. For example, Fiedler's (1978) cognitive-resource theory assumes such a contingency. Fiedler predicts that leaders who are more relationship oriented will be more effective than leaders who are task focused when there is moderate situational control; in contrast, leaders who are more task focused will be more effective in situations in which there is either high or low situational control. Fiedler also has looked at effects of intelligence. According to Fiedler, the correlation of intelligence with leadership 
success is moderated by a number of factors. One such factor is the stress experienced by the leader (Fiedler, 2002; Fiedler and Link, 1994), which apparently even can change the direction of the correlation. Intelligence positively predicts leadership success under conditions of low stress, but not high stress, where it may actually impede effectiveness. There is also some evidence that when a leader's cognitive skills are substantially higher than those of his or her followers, higher levels of cognitive skills may actually work against the leader's effectiveness (Simonton, 1994; Williams and Sternberg, 1988). For example, a highly intelligent superintendent might find her intelligence working against her if her preference is to apply careful and complete analysis to situations that provide neither the time nor the resources to allow such a preference to take root.

Another theory that emphasizes the interaction between a leader and the situation is that of Vroom (Vroom and Jago, 1978; Vroom and Yetton, 1973). This theory specifies what a leader's behavior should be as a function of the kind of situation he or she is in, for example, with regard to his or her own knowledge and that of the people he or she leads. Vroom's theory is based on five general strategies, two of which are autocratic, two of which are consultative, and one of which involves full participation of the group. The leader chooses a form of leadership based on four criteria, namely: improving the quality of decision making, increasing involvement of subordinates, reducing time spent in decision making, and developing subordinates. How consultative a principal should be, for example, would depend on the skill of the teachers he or she works with, how much pressure there is to reach a decision quickly, how much consultation the principal is comfortable in making, and so forth.

Path-goal theory, proposed by House (1971, 1996), identifies four types of leadership styles: directive, achievement oriented, supportive, and participative. The first two styles are more task oriented, the second two more relationship oriented. Which style works best depends on characteristics of the environment and of the followers one is to lead.

Yukl (1994) has suggested a number of variables that can enhance or diminish the effects of intervening variables in leadership. They include things such as recruitment and selection systems, geographical dispersion of the work unit, the nature of the flow of work, the size of the team, and team member characteristics.

Contingency theories represent the need for leaders to interact with the situation they are in. They remain one of the most popular kinds of theorizing today. The most difficult challenge they face is that of whether $\mathrm{ev}$ erything is an interaction. Probably that is not the case. For example, some reasonably high level of intelligence and openness to experience is probably associated with good leadership under most circumstances. To the extent 
that a theory turns everything into a contingency, it may become difficult to do what science needs to do-which is to provide a model that, in some way, reduces a phenomenon. At the extreme, if everything were a contingency, there would be nothing general to teach leaders. Nevertheless, this approach seems to be superior in recognizing that many attributes of leaders do indeed interact with situations.

\section{Transformational Leadership Approaches}

Transformational approaches to leadership originate in the work of Burns (1978). Burns suggested that there are essentially two ways of performing leadership functions. One is where there is an implicit or explicit contractual relationship between the leader and his or her followers. This type of leadership, which has come to be called transactional leadership, is characterized by followers agreeing to do certain stipulated things in exchange for the leader (usually a boss) doing other things. A second and more powerful kind of transformational leadership tries to gain converts to ideas.

Thus, transactional leaders emphasize the contractual relationship between leader and follower. For example, an employee might agree to engage in certain activities in exchange for certain rewards from the leadership of the organization by which he is employed (Sashkin, 2004). A transactional principal makes clear what he or she expects of his or her teachers. In exchange, those teachers who do what is expected of them will be adequately compensated and potentially be given benefits, such as better classes to teach, or a less demanding schedule. Transformational leaders emphasize higher needs, such as for self-actualization, and a leaderfollower relationship in which followers may become leaders, and leaders, moral agents (Burns, 1978; Sashkin, 2004). In the terms of Bass and Avolio (Bass, 1985, 1998, 2002; Bass and Avolio, 1994; Bass et al., 1996), transactional leaders are more likely to pursue options that preserve current paradigms. Transformational leaders, on the other hand, are more likely to pursue any options that reject current paradigms. They are crowd-defiers. In terms of Kuhn's (1970) theory of scientific revolutions, which applies to ideas outside the sciences as well, transformational leaders revolutionize ways of thinking. They change the systems in which they work, whether they are classrooms, schools, or entire school systems.

Bass (1985) suggested that transactional and transformational leadership are not two opposite ends of a single continuum, but rather, two independent aspects of leadership. Bass developed a widely used measure, the Multifactor Leadership Questionnaire (MLQ), which assesses transactional 
and transformational aspects of leadership. In its latest form (Bass and Avolio, 1995), it yields five factors: idealized influence-attributions, idealized influence-behaviors, individualized consideration, intellectual stimulation, and inspirational motivation.

The transformational approach is currently popular and shows that good leadership is much more than good management. At the same time, it addresses only limited aspects of leadership. Not all organizations need to be transformed at a given time, and not all leaders who succeed are transformational. Indeed, there may be times when transformation is counter indicated, as when an organization is having great success in what it is doing or when times are such that resources are not available for substantial change. A successful school may not want to change because it has found a recipe for success. Thus, this theory addresses important aspects of leadership rather than leadership as a whole.

\section{The Leading-Minds Approach to Leadership}

Howard Gardner (1993a,b, 1995) has proposed a theory of leadership based on multiple intelligences that takes a distinctly cognitive approach to understanding leadership.

\section{Multiple Intelligences}

In his earlier work, Gardner (1993b) sought to apply his theory of multiple intelligences to understanding leadership and especially creative leadership. The theory proposes that intelligence can be understood as comprising eight or possibly nine distinct intelligences, each of which constitutes a separate symbol system. Linguistic intelligence is used in verbal communication, such as to understand newspaper articles, to write poetry, or speak articulately. Gardner used T. S. Eliot as an example of a creative leader in the linguistic domain. Logical/mathematical intelligence is used in posing and solving mathematical and logical problems. According to Gardner, Einstein was a creative leader in this domain. Bodily-kinesthetic intelligence is used in skilled physical activity, such as basketball, dance, and acrobatics. Gardner used Martha Graham as an example of a creative leader in this intelligence. Spatial intelligence is used in understanding space and form. Gardner held up Pablo Picasso as a master of this intelligence. Musical intelligence is used to read music, play an instrument, or sing a song. Gardner used Igor Stravinsky as an example of a creative leader in this intelligence. Interpersonal intelligence is used to understand other 
people and interact with them. Gardner used Mahatma Gandhi as an example of it. Intrapersonal intelligence is key to self-understanding. Gardner used Sigmund Freud as an example. After writing his 1993 book, Gardner (1999) added two more intelligences. Naturalist intelligence is used to understand patterns in nature, and, according to Gardner, is well exemplified by Charles Darwin. Existential intelligence, a so-called "candidate intelligence," is used to understand deeper issues of meaning in life, and might be particularly well exemplified by individuals such as Gautama Buddha.

\section{Six Constants of Leadership}

Gardner (1995) suggests that there are six constants of leadership. Different leaders excel in them to different degrees.

The first is a story. The leader must have a story to tell or some kind of message to convey. The story is more effective to the extent that it appeals to what Gardner (1991) refers to as the "unschooled mind," that is, a mind that, in terms of modern cognitive theory, is more experiential than rational in its thinking (Sloman, 1996). Stories need to address both individuals' own identities and those of the group or groups to which they belong. A story is more likely to succeed if it is central to what the leader actually does in his or her action, if the story can be unfolded over a long period of time, and if it can be stated in a time of relative calm. In times of crisis, according to Gardner, stories need to be simplified.

Stories may be inclusionary or exclusionary. Inclusionary leaders try to ensure that all of the followers for whom they are responsible somehow are made to feel inside the fold. Exclusionary leaders do not include everyone and in extreme cases, such as Hitler or Stalin, turn on segments of the population whom they are entrusted to lead.

The second constant is the audience. Gardner (1995) points out that no matter what the story, if there is no audience for it, it is dead. So a leader needs a story to which his or her audience will respond. The leader needs to take into account the experiential mode of thinking of the audience, and the kinds of changes in points of view to which the audience is likely to be responsive.

The third constant is the organization. Sooner or later, a leader needs some kind of organization or other institutional support. Sometimes, the leader starts with such backing. Other times, the leader must acquire the backing. Gardner points out that dictatorial leaders, such as Stalin, would have gotten nowhere without an organization to enforce their will. Nontotalitarian leaders, such as Churchill, discover that if they lose organizational support, they risk losing their hold on leadership. 
The fourth constant is what Gardner refers to as the embodiment. The leader must in some way embody the story he or she tells. If the leader fails to do so, then that leader's leadership may be seen as bankrupt. For example, cover ups by Richard Nixon and Bill Clinton seriously undermined their leadership because they came to be seen as leaders who held others to one standard, and themselves to another. Many people recently have lost faith in certain church leaders who held their flocks to a standard of morality that they themselves flagrantly violated by abusing children or covering up such abuse. One cannot lead effectively if one asks people to do as one says, not as one does.

The fifth constant is direct and indirect leadership. In direct leadership, one has power of some kind over those whom one leads, as is the case for individuals in government positions. In indirect leadership, one's power stems from the symbolic products one creates. For example, the literary leadership of T. S. Eliot or the musical leadership of Igor Stravinsky was indirect. Most leaders are indirect. Their power is not necessarily lesser as a result. For example, Jesus was an indirect leader, yet one of the most powerful leaders in all of history.

The sixth constant is expertise (Sternberg, 1998d). A leader needs knowledge of a domain in order to lead effectively. As Gardner points out, direct leaders often have indirect knowledge; they tend to rely on the expertise of staff and other subordinates. Indirect leaders more often have direct knowledge; they themselves are experts.

\section{Guidelines for Effective Leadership}

Gardner (1995) proposes three general guidelines for effective leadership.

The first is to appreciate the enduring features of leadership. This means recognizing and appreciating the importance of the six constants mentioned earlier. If one loses sight of these features, one may also lose one's effectiveness as a leader.

The second is to anticipate and deal with new trends. Many leaders are effective at one point in time, only to lose their effectiveness and later find that they no longer have their audience. Often they have failed to cope with the changes that can happen so rapidly in the world. Thus, they cannot take their mantle of leadership for granted. They must continually reinvent it.

The third is to encourage recognition of the problems, paradoxes, and possibilities of leadership. A leader needs to educate his or her audience. At the same time, he or she must recognize what a difficult task this is, given the unschooled minds of most followers. There are many paradoxes 
in leadership, according to Gardner. One is the tension between technical expertise, on the one hand, and the need to reach the unschooled mind, on the other. Another is the need for stories that speak to many yet diverse individuals. A third is the problem that stories can build a community, or fragment it. Sometimes, there are factions that would prefer that the audience be fractionated. So a leader must live in a dialectical world in which unruly complications are the exception rather than the rule.

\section{A Typical Exemplary Leader}

Gardner (1995) has characterized what he refers to as an exemplary leader (EL). This leader is a persuasive speaker and is interested in understanding other people and how they think. The individual is energetic and resourceful and as a youngster, seems to be someone on the road to success, although it is not yet clear what form this success will take. Typically, the leader is well rounded rather than particularly strong in one particular area, although there are exceptions. The EL is willing when necessary to confront people in authority and may even do so in an abrasive way. Often, the EL feels superior in some sense toward others. ELs often lost their fathers at an early age and this loss may be part of what they feel empowers them to exercise the authority that the father is no longer there to exercise. ELs are open to experience and typically have many and diverse experiences before they actually enter into positions of leadership. He or she is attuned to the audience and sees how to capitalize on his or her experiences in creating a story that will resonate with the audience. The EL recognizes that one does not simply plop down into a position where he or she commands respect. Rather, it must be earned and then re-earned. The EL, thus, is aware of changes in the environment and capitalizes on these changes to renew his or her leadership.

\section{Leaders Changing Minds}

In his most recent work, Gardner (2004) has enumerated the steps leaders must take in order to change the minds of their followers. The first step is research. People can be persuaded by data. The second step is overcoming resistances. Leaders must expect groups of followers to resist some of the leaders' ideas. It is the leaders' responsibility to devise ways to overcome these resistances. The third step is becoming aware of resources and rewards. What does the leader have at his or her disposal to sweeten the pie-to encourage people to follow his or her leadership? 
The fourth step is representational redescription. Ideas can be expressed in many ways. The more different ways in which a leader's ideas can be expressed, and the more compelling these ways are, the more likely the leader is to persuade followers to come along. The fifth step is reason. The leader needs to be prepared to reason with followers in order to persuade them to follow. The sixth step is resonance. At a given time and in a given place, certain ideas will resonate with followers, others will not. Establishing resonance can go a long way toward persuading people to listen. And the final step is incorporating real-world events. Followers need to see how the leader's ideas relate to the lives the followers live from day to day.

Having considered some of the main approaches to leadership, next consider the WICS theory, first through cognitive processing and then through stories of leadership on which the processes act.

\section{THE WICS MODEL}

The WICS model is a possible common basis for identifying positive educational leaders, both developed and in development. This model is an expansion of a model of abilities for leadership proposed elsewhere (Sternberg, 2003c,d,e,f, 2004b; Sternberg and Vroom, 2002). WICS, as noted earlier, is an acronym standing for wisdom, intelligence, and creativity, synthesized. It builds upon many of the models described earlier, but is different in systematically trying to combine wisdom, intelligence, and creativity, which are, separately, implicit in many previous models. According to the WICS model, wisdom, intelligence, and creativity synthesized provide a sine qua non for the positive educational leaders of the past, present, and future. Without a synthesis of these three attributes, someone can be a decent educational leader, and perhaps even a good one, but never a great one. A great educational leader uses creativity to generate possible depictions and solutions of problems; analytical intelligence to evaluate the quality of these depictions and solutions; practical intelligence to implement decisions and persuade others of their value; and wisdom to ensure the decisions help achieve a common good.

The history of the theory presented here has been documented, to some extent, in two earlier theoretical articles (Sternberg, 1980b, 1984). In the first article (Sternberg, 1980b), a theory of components of intelligence was presented, arguing that intelligence could be understood in terms of a set of elementary information-processing components that contributed to people's intelligence and individual differences in it. In the second article (Sternberg, 1984), the theory was expanded to include not just the analytical 
aspect of intelligence, which had been the emphasis of the earlier article, but the creative and practical aspects of intelligence as well. But I came to realize that intelligence, and even what I came to call successful intelligence, are not enough for positive educational leadership. Consider the role of a politician in educating his or her citizenry. Stalin was successfully intelligent in his own societal context, but he was not an educational leader, and certainly not a positive one. The current article extends the theory to encompass creativity and wisdom in synthesis with each other and with intelligence.

In the remainder of this article, each of these attributes is discussed, although for didactic purposes, they are not discussed in the order in which they are stated earlier. The discussion starts with intelligence, which is a basis for creativity and for wisdom and so should be discussed first. Next creativity is discussed, which is essential as well for wisdom. Then, wisdom is discussed, which builds on but goes beyond intelligence and creativity. Finally, some general conclusions are drawn.

\section{Intelligence}

\section{The Nature of Intelligence}

There are many definitions of intelligence, although intelligence is typically defined in terms of a person's ability to adapt to the environment and to learn from experience (Sternberg and Detterman, 1986). The definition of intelligence here is somewhat more elaborate and is based on my (Sternberg, 1997, 1998a, 1999c) theory of successful intelligence. According to this definition, (successful) intelligence is (1) the ability to achieve one's goals in life, given one's sociocultural context; (2) by capitalizing on strengths and correcting or compensating for weaknesses; (3) in order to adapt to, shape, and select environments; (4) through a combination of analytical, creative, and practical abilities.

Consider first Item 1. Intelligence involves formulating a meaningful and coherent set of goals, and having the skills and dispositions to reach those goals. One individual may wish to be a statesperson, another, a scientist, and still another, an artist. Others may decide on careers in athletics, plumbing, politics, acting, or whatever. The question typically is not so much what goals individuals have chosen, but rather, what the individuals have done so that they can realize those goals in a meaningful way. Thus, this item actually includes three sub-items: (a) identifying meaningful goals; (b) coordinating those goals in a meaningful way so that they form a coherent story of what one is seeking in life; and (c) moving a substantial distance along the path toward reaching those goals. 
This first item recognizes that "intelligence" means a somewhat different thing to each individual. The individual who wishes to become a Supreme Court judge will be taking a different path from the individual who wishes to become an educational leader-but both will have formulated a set of coherent goals toward which to work. An evaluation of intelligence should focus not on what goal is chosen but on whether the individual has chosen a worthwhile set of goals and shown the skills and dispositions needed to achieve them.

Item 2 recognizes that although psychologists sometimes talk of a "general" factor of intelligence (Jensen, 1998; Spearman, 1927; see essays in Sternberg, 2000; Sternberg and Grigorenko, 2002b), really, virtually no one is good at everything or bad at everything. People who are the positive educational leaders of society have identified their strengths and weaknesses, and have found ways to work effectively within that pattern of abilities.

There is no single way to succeed in a job that works for everyone. For example, some principals are successful by virtue of their strong analytical skills. They can figure out the problems their schools are confronting, and what aspects of the school are working better and worse. Other leaders may be successful by their creative intellectual skills. They may not be the best at figuring out what is right and wrong in the present system. But they may be strong in figuring out a vision for what needs to be done. And still other principals are strong in practical skills. They get along well with people and/or know how to implement the programs their school has adopted.

This same general principle applies in any profession. Consider, for example, teaching. Educators often try to distinguish characteristics of expert teachers (see Sternberg and Williams, 2001), and indeed, they have distinguished some such characteristics. But the truth is that teachers can excel in many different ways. Some teachers are better in giving large lectures; others in small seminars; others in one-on-one mentoring. There is no one formula that works for every teacher. Good teachers figure out their strengths and try to arrange their teaching so that they can capitalize on their strengths and at the same time either compensate for or correct their weaknesses. Team teaching is one way of doing so, in that one teacher can compensate for what the other does not do well.

Candidates for positions of positive educational leadership might have different patterns of abilities. Sometimes selection committees will have feelings of discomfort, recognizing that they are obliged to choose between "apples and oranges"- that is, to evaluate people whose strengths are drastically different on a single scale that does not seem to apply across all applicants. For example, one candidate may excel in creativity, another in interpersonal skills. The two dimensions do no collapse well into one scale. When the committee looks at their task from the standpoint of the 
theory of successful intelligence, their job becomes easier. The question is not how well people do on some common scale, but rather, how well they do on whatever scales are relevant to their making the most of their own aspirations-in other words, how well they capitalize on their strengths without letting their weaknesses get in their way. Of course, they further need to reflect on other attributes that may be required over and above intelligence.

Item 3 recognizes that intelligence broadly defined refers to more than just "adapting to the environment," which is the mainstay of conventional definitions of intelligence. The theory of successful intelligence distinguishes among adapting, shaping, and selecting.

In adaptation to the environment, one modifies oneself to fit an environment. The ability to adapt to the environment is important in life, and is especially important to individuals entering a new program. Most of them will be entering a new environment that is quite different from the one in which they previously have spent time. If they are not adaptable, they may not be able to transfer the skills they showed in the previous environment to the new one. Over the course of a life-time, environmental conditions change greatly. A kind of work that at one point in time may be greatly valued (e.g., forming a start-up company) may, at another point in time, be valued little if at all. In research, the problems change, and sometimes, people who were effective in solving the problems of one decade are relatively ineffective in solving the problems of another decade. In governmental leadership, some elected leaders prove to be dinosaurs-people who were able to lead the country effectively under one set of conditions but not under another set of conditions (such as when the national or world economy tanks). Clearly, adaptability is a key skill in any definition of intelligence. An educational leader ought to be able to show the ability to adapt to a variety of environments.

In life, adaptation is not enough, however. Adaptation needs to be balanced with shaping. In shaping, one modifies the environment to fit what one seeks of it, rather than modifying oneself to fit the environment. Truly great educational leaders are not just adaptors; they are also shapers. They recognize that they cannot change everything, but that if they want to have an impact on the world, they have to change some things. Part of successful intelligence is deciding what to change, and then how to change it.

When an individual enters an institution, one hopes that the individual will not only adapt to the environment, but shape it in a way that makes it a better place than it was before. Selection committees look for evidence not just of a candidate's engagement in a variety of activities but also of the individual's having made a difference in those activities. Through shaping, one has this kind of impact (see Sternberg, 2003a). 
Sometimes, one attempts unsuccessfully to adapt to an environment and then also fails in shaping that environment. No matter what one does to try to make the environment work out, nothing in fact seems to work. In such cases, the appropriate action may be to select another environment.

Many of the greatest people in any one field are people who started off in another field and found that the first field was not really the one in which they had the most to contribute. Nobel Prize winner Herbert Simon is a good example. He started off working in mathematics and economics, and then later worked in political science, and then in computer science and psychology. Rather than spend their lives doing something that turned out not to match their pattern of strengths and weaknesses, they had the sense to find something else to do where they really had a contribution to make.

Item 4 points out that successful intelligence involves a broader range of abilities than is typically measured by tests of intellectual and academic skills. Most of these tests measure primarily or exclusively memory and analytical abilities. With regard to memory, they assess the abilities to recall and recognize information. With regard to analytical abilities, they measure the skills involved when one analyzes, compares and contrasts, evaluates, critiques, and judges. These are important skills during the school years and in later life. But they are not the only skills that matter for school and life success. People need not only to remember and analyze concepts, they need to be able to generate and apply them. Memory pervades analytic, creative, and practical thinking, and is necessary for their execution; but it is far from sufficient.

According to the proposed theory of human intelligence and its development (Sternberg, 1980b, 1984, 1985a, 1990, 1997, 1999a, 2003e, 2004a), a common set of processes underlies all aspects of intelligence. These processes are hypothesized to be universal. For example, although the solutions to problems that are considered intelligent in one culture may be different from the solutions considered to be intelligent in another culture, the need to define problems and translate strategies to solve these problems exists in any culture.

Metacomponents, or executive processes, plan what to do, monitor things as they are being done, and evaluate things after they are done. Examples of metacomponents are recognizing the existence of a problem, defining the nature of the problem, deciding on a strategy for solving the problem, monitoring the solution of the problem, and evaluating the solution after the problem is solved.

Performance components. execute the instructions of the metacomponents. For example, inference is used to decide how two stimuli are related, and application is used to apply what one has inferred (Sternberg, 1977). 
Other examples of performance components are comparison of stimuli, justification of a given response as adequate although not ideal, and actually making the response.

Knowledge-acquisition components are used to learn how to solve problems or simply to acquire declarative knowledge in the first place (Sternberg, 1985a). Selective encoding is used to decide what information is relevant in the context of one's learning. Selective comparison is used to bring old information to bear on new problems. And selective combination is used to put together the selectively encoded and compared information into a single and sometimes insightful solution to a problem.

Although the same processes are used for all three aspects of intelligence universally, these processes are applied to different kinds of tasks and situations depending on whether a given problem requires analytical thinking, creative thinking, practical thinking, or a combination of these kinds of thinking. In particular, analytical thinking is invoked when components are applied to fairly familiar kinds of problems abstracted from everyday life. Creative thinking is invoked when the components are applied to relatively novel kinds of tasks or situations. Practical thinking is invoked when the components are applied to experience to adapt to, shape, and select environments. One needs creative skills and dispositions to generate ideas, analytical skills and dispositions to decide if they are good ideas, and practical skills and dispositions to implement one's ideas and to convince others of their worth.

More details regarding the theory can be found in Sternberg (1984, 1985a, 1997). Because the theory of successful intelligence comprises three subtheories-a componential subtheory dealing with the components of intelligence, an experiential subtheory dealing with the importance of coping with relative novelty and of automatization of information processing, and a contextual subtheory dealing with processes of adaptation, shaping, and selection - the theory has been referred to from time to time as triarchic.

Intelligence is not, as Edwin Boring (1923) once suggested, merely what intelligence tests test. Intelligence tests and other tests of cognitive and academic skills measure part of the range of intellectual skills. They do not measure the whole range. One should not conclude that a person who does not test well is not smart. Rather, one should merely look at test scores as one indicator among many of a person's intellectual skills.

\section{The Assessment of Intelligence}

Our assessments of intelligence have been organized around the analytical, creative, and practical aspects of it. I discuss those assessments here. 


\section{Analytical Intelligence}

Analytical intelligence is involved when the information-processing components of intelligence are applied to analyze, evaluate, judge, or compare and contrast. It typically is involved when components are applied to relatively familiar kinds of problems where the judgments to be made are of a fairly abstract nature.

In some early work, it was shown how analytical kinds of problems, such as analogies or syllogisms, can be analyzed componentially (Guyote and Sternberg, 1981; Sternberg, 1977, 1980b, 1983; Sternberg and Gardner, 1983; Sternberg and Turner, 1981), with response times or error rates decomposed to yield their underlying information-processing components. The goal of this research was to understand the information-processing origins of individual differences in (the analytical aspect of) human intelligence. With componential analysis, one could specify sources of individual differences underlying a factor score such as that for "inductive reasoning." For example, response times on analogies (Sternberg, 1977) and linear syllogisms (Sternberg, 1980a) were decomposed into their elementary performance components. The general strategy of such research is to (a) specify an information-processing model of task performance; (b) propose a parameterization of this model, so that each information-processing component is assigned a mathematical parameter corresponding to its latency (and another corresponding to its error rate); and (c) construct cognitive tasks administered in such a way that it is possible through mathematical modeling to isolate the parameters of the mathematical model. In this way, it is possible to specify, in the solving of various kinds of problems, several sources of important individual or developmental differences: (1) What performance components are used? (2) How long does it take to execute each component? (3) How susceptible is each component to error? (4) How are the components combined into strategies? (5) What are the mental representations upon which the components act?

As an example, through componential analysis, it was possible to decompose inductive-reasoning performance into a set of underlying information-processing components. The analogy $A: B:: C: D$, $D 1, D 2, D 3, D 4$ is used as an example to illustrate the components. These components are (1) encoding, the amount of time needed to register each stimulus ( $A, B, C, D 1, D 2, D 3, D 4)$; (2) inference, the amount of time needed to discern the basic relation between given stimuli ( $A$ to $B)$; (3) mapping, the amount of time needed to transfer the relation from one set of stimuli to another (needed in analogical reasoning) ( $A$ to $C$ ); (4) application, the amount of time needed to apply the relation as inferred (and sometimes as mapped) to a new set of stimuli ( $A$ to $B$ as $C$ to ?); (5) comparison, 
the amount of time needed to compare the validity of the response options (D1, D2, D3, D4); (6) justification, the amount of time needed to justify one answer as the best of the bunch (e.g., D1); and (7) preparation-response, the amount of time needed to prepare for problems solution and to respond.

Studies of reasoning need not use artificial formats. In a more recent study, a colleague and I looked at predictions for everyday kinds of situations, such as when milk will spoil (Sternberg and Kalmar, 1997). In this study, the investigators looked at both predictions and postdictions (hypotheses about the past where information about the past is unknown) and found that postdictions took longer to make than did predictions.

Research on the components of human intelligence yielded some interesting results. Consider some examples. First, execution of early components (e.g., inference and mapping) tends exhaustively to consider the attributes of the stimuli, whereas execution of later components (e.g., application) tends to consider the attributes of the stimuli in self-terminating fashion, with only those attributes processed that are essential for reaching a solution (Sternberg, 1977). Second, in a study of the development of figural analogical reasoning, it was found that although children generally became quicker in information processing with age, not all components were executed more rapidly with age (Sternberg and Rifkin, 1979). The encoding component first showed a decrease in component time with age and then an increase. Apparently, older children realized that their best strategy was to spend more time in encoding the terms of a problem so that they later would be able to spend less time in operating on these encodings. A related, third finding was that better reasoners tend to spend relatively more time than do poorer reasoners in global, up-front metacomponential planning when they solve difficult reasoning problems. Poorer reasoners, on the other hand, tend to spend relatively more time in local planning (Sternberg, 1981). Presumably, the better reasoners recognize that it is better to invest more time up front so as to be able to process a problem more efficiently later on. Fourth, it also was found in a study of the development of verbal analogical reasoning that as children grew older, their strategies shifted so that they relied on word association less and abstract relations more (Sternberg and Nigro, 1980).

Some of the componential studies concentrated on knowledgeacquisition components rather than performance components or metacomponents. For example, in one set of studies, the investigators were interested in sources of individual differences in vocabulary (Sternberg and Powell, 1983; Sternberg et al., 1983; see also Sternberg, 1987a,b). We were not content just to view these as individual differences in declarative knowledge because we wanted to understand why it was that some people acquired this declarative knowledge and others did not. What we found was 
that there are multiple sources of individual and developmental differences. The three main sources were in knowledge-acquisition components, use of context clues, and use of mediating variables. For example, in the sentence, "The blen rises in the east and sets in the west," the knowledge-acquisition component of selective comparison is used to relate prior knowledge about a known concept, the sun, to the unknown word (neologism) in the sentence, "blen." Several context cues appear in the sentence, such as the fact that a blen rises, the fact that it sets, and the information about where it rises and sets. A mediating variable is that the information can occur after the presentation of the unknown word.

We did research such as that described earlier because they believed that conventional psychometric research sometimes incorrectly attributed individual and developmental differences. For example, a verbal analogies test that might appear on its surface to measure verbal reasoning might in fact measure primarily vocabulary and general information (Sternberg, 1977). In fact, in some populations, reasoning might hardly be a source of individual or developmental differences at all. And if researchers then look at the sources of the individual differences in vocabulary, they would need to understand that the differences in knowledge did not come from nowhere: Some children had much more frequent and better opportunities to learn word meanings than did others.

In the componential-analysis work described earlier, correlations were computed between component scores of individuals and scores on tests of different kinds of psychometric abilities. First, in the studies of inductive reasoning (Sternberg, 1977; Sternberg and Gardner, 1982, 1983), it was found that although inference, mapping, application, comparison, and justification tended to correlate with such tests, the highest correlation typically was with the preparation-response component. This result was puzzling at first because this component was estimated as the regression constant in the predictive regression equation. This result ended up giving birth to the concept of the metacomponents: higher-order processes used to plan, monitor, and evaluate task performance. It was also found, second, that the correlations obtained for all the components showed convergent-discriminant validation: They tended to be reliably related with psychometric tests of reasoning but not with psychometric tests of perceptual speed (Sternberg, 1977; Sternberg and Gardner, 1983). Moreover, third, significant correlations with vocabulary tended to be obtained only for encoding of verbal stimuli (Sternberg, 1977, Sternberg and Gardner, 1983). Fourth, it was found in studies of linear-syllogistic reasoning (e.g., John is taller than Mary; Mary is taller than Susan; who is tallest?) that components of the proposed (mixed linguistic-spatial) model that were supposed to correlate with verbal ability did so but did not correlate with spatial ability; components that 
were supposed to correlate with spatial ability did so but did not correlate with verbal ability. In other words, it was possible successfully to validate the proposed model of linear-syllogistic reasoning not only in terms of the fit of response-time or error data to the predictions of the alternative models but also in terms of the correlations of component scores with psychometric tests of verbal and spatial abilities (Sternberg, 1980a). Fifth and finally, it was found that there were individual differences in strategies in solving linear syllogisms, whereby some people used a largely linguistic model, others a largely spatial model, and most the proposed linguistic-spatial mixed model. Thus, sometimes, less than perfect fit of a proposed model to group data may reflect individual differences in strategies among participants.

\section{Creative Intelligence}

Intelligence tests contain a range of problems, some of them more novel than others. In some of the componential work we have shown that when one goes beyond the range of unconventionality of the conventional tests of intelligence, one starts to tap sources of individual differences measured little or not at all by the tests. According to the theory of successful intelligence, (creative) intelligence is particularly well measured by problems assessing how well an individual can cope with relative novelty. Thus, it is important to include in a battery of tests problems that are relatively novel in nature.

We (Sternberg, 1982) presented 80 individuals with novel kinds of reasoning problems that had a single best answer. For example, they might be told that some objects are green and others blue; but still other objects might be grue, meaning green until the year 2000 and blue thereafter, or bleen, meaning blue until the year 2000 and green thereafter. Or they might be told of four kinds of people on the planet Kyron, blens, who are born young and die young; kwefs, who are born old and die old; balts, who are born young and die old; and prosses, who are born old and die young. Their task was to predict future states from past states, given incomplete information (see also Tetewsky and Sternberg, 1986). In another set of studies, 60 people were given more conventional kinds of inductive reasoning problems, such as analogies, series completions, and classifications, but were told to solve them. The problems, though, had premises preceding them that were either conventional (dancers wear shoes) or novel (dancers eat shoes). The participants had to solve the problems as though the counterfactuals were true (Sternberg and Gastel, 1989a,b).

In these studies, we found that correlations with conventional kinds of tests depended on how novel or nonentrenched the conventional tests were. The more novel are the items, the higher are the correlations of our tests 
with scores on successively more novel conventional tests. Thus, the components isolated for relatively novel items would tend to correlate more highly with more unusual tests of fluid abilities (e.g., that of Cattell and Cattell, 1973) than with tests of crystallized abilities. We also found that when response times on the relatively novel problems were componentially analyzed, some components better measured the creative aspect of intelligence than did others. For example, in the "grue-bleen" task mentioned earlier, the information-processing component requiring people to switch from conventional green-blue thinking to grue-bleen thinking and then back to green-blue thinking again was a particularly good measure of the ability to cope with novelty.

\section{Practical Intelligence}

Practical intelligence involves individuals applying their abilities to the kinds of problems that confront them in daily life, such as on the job or in the home. Practical intelligence involves applying the components of intelligence to experience so as to (a) adapt to, (b) shape, and (c) select environments. Adaptation is involved when one changes oneself to suit the environment. Shaping is involved when one changes the environment to suit oneself. And selection is involved when one decides to seek out another environment that is a better match to one's needs, abilities, and desires. People differ in their balance of adaptation, shaping, and selection, and in the competence with which they balance among the three possible courses of action.

Much of our work on practical intelligence has centered on the concept of tacit knowledge (Sternberg et al., 2000). We have defined this construct as what one needs to know in order to work effectively in an environment that one is not explicitly taught in school or at work and that often is not even verbalized explicitly (Sternberg et al., 1993, 1995, 2000; Sternberg and Wagner, 1993; Wagner, 1987; Wagner and Sternberg, 1986). An example of tacit knowledge would be knowing that if teachers are asked to do too many new things to improve their teaching, they may become confused and teach less rather than more effectively.

We typically have measured tacit knowledge using work-related problems that present problems one might encounter on the job. We have measured tacit knowledge for both children and adults, and among adults, for people in over two dozen occupations, such as management, sales, academia, teaching, school administration, secretarial work, and the military. In a typical tacit-knowledge problem, people are asked to read a story about a problem someone faces and to rate, for each statement in a set of statements, how adequate a solution the statement represents. For example, 
in a paper-and-pencil measure of tacit knowledge for sales, one of the problems deals with sales of photocopy machines. A relatively inexpensive machine is not moving out of the show room and has become overstocked. The examinee is asked to rate the quality of various solutions for moving the particular model out of the show room. In a performance-based measure for sales people, the test-taker makes a phone call to a supposed customer, who is actually the examiner. The test-taker tries to sell advertising space over the telephone. The examiner raises various objections to buying the advertising space. The test-taker is evaluated for the quality, rapidity, and fluency of the responses on the telephone.

In the tacit-knowledge studies (reviewed in Sternberg et al., 2000), we found, first, that practical intelligence as embodied in tacit knowledge increases with experience, but it is profiting from experience rather than experience per se that results in increased scores. Some people can have been in a job for years and still have acquired relatively little tacit knowledge. Second, we also found that subscores on tests of tacit knowledge-such as for managing oneself, managing others, and managing tasks-correlate significantly with each other. Third, scores on various tests of tacit knowledge, such as for academics and managers, are also correlated fairly substantially (at about the 0.5 level) with each other. Thus, fourth, tests of tacit knowledge may yield a general factor across these tests. However, fifth, scores on tacit-knowledge tests do not correlate with scores on conventional tests of intelligence, whether the measures used are single-score measures or multiple-ability batteries. Thus, any general factor from the tacit-knowledge tests is not the same as any general factor from tests of academic abilities (suggesting that neither kind of $g$ factor is truly general, but rather, general only across a limited range of measuring instruments). Sixth, despite the lack of correlation of practical-intellectual with conventional measures, the scores on tacit-knowledge tests predict performance on the job as well as or better than do conventional psychometric intelligence tests. We further found, seventh, that scores on our tests of tacit knowledge for management were the best single predictor of performance on a managerial simulation. In a hierarchical regression, scores on conventional tests of intelligence, personality, styles, and interpersonal orientation were entered first and scores on the test of tacit knowledge were entered last. Scores on the test of tacit knowledge were the single best predictor of managerial simulation score. Moreover, these scores also contributed to the prediction even after everything else was entered first into the equation. In recent work on military leadership (Hedlund et al., 2003; Sternberg and Hedlund, 2002; Sternberg et al., 2000), it was found, eighth, that scores of 562 participants on tests of tacit knowledge for military leadership predicted ratings of leadership effectiveness, whereas scores on a conventional test of 
intelligence and on a tacit-knowledge test for managers did not significantly predict the ratings of effectiveness.

We also have done studies of social intelligence, which is viewed in the theory of successful intelligence as a part of practical intelligence (Barnes and Sternberg, 1989; Sternberg and Smith, 1985). In these studies, 40 individuals were presented with photos and were asked to make judgments about the photos. For one kind of photo, they were asked to evaluate whether a male-female couple was a genuine couple (i.e., really involved in a romantic relationship) or a phony couple posed by the experimenters. For another kind of photo, they were asked to indicate which of two individuals was the other's supervisor. Females were superior to males on these tasks. Scores on the two tasks did not correlate with scores on conventional ability tests, nor did they correlate with each other, suggesting a substantial degree of domain specificity in the task.

Even stronger results were obtained overseas. In a study in Usenge, Kenya, near the town of Kisumu, we examined school-age children's ability to adapt to their indigenous environment. We devised a test of practical intelligence for adaptation to the environment (see Sternberg and Grigorenko, 1997; Sternberg et al., 2001b). The test of practical intelligence measured children's informal tacit knowledge for natural herbal medicines that the villagers believe can be used to fight various types of infections. At least some of these medicines appear to be effective (Dr. Frederick Okatcha, personal communication), and most villagers certainly believe in their efficacy, as shown by the fact that children in the villages use their knowledge of these medicines an average of once a week in medicating themselves and others. Thus, tests of how to use these medicines constitute effective measures of one aspect of practical intelligence as defined by the villagers as well as their life circumstances in their environmental contexts. Middle-class Westerners might find it quite a challenge to thrive or even survive in these contexts, or, for that matter, in the contexts of urban ghettos often not distant from their comfortable homes.

We measured the Kenyan children's ability to identify the medicines, where they come from, what they are used for, and how they are dosed. Based on work we had done elsewhere, we expected that scores on this test would not correlate with scores on conventional tests of intelligence (Sternberg et al., 2000). In order to test this hypothesis, we also administered to 85 children the Raven Coloured Progressive Matrices Test, which is a measure of fluid or abstract-reasoning-based abilities, as well as the Mill Hill Vocabulary Scale, which is a measure of crystallized or formalknowledge-based abilities. In addition, we gave the children a comparable test of vocabulary in their own Dholuo language. The Dholuo language is spoken in the home; English is spoken in the schools. 
We did indeed find no correlation between the test of indigenous tacit knowledge and scores on the fluid-ability tests. But to our surprise, we found negative correlations between the tacit-knowledge tests and scores on the tests of crystallized abilities. In other words, on average the higher the children scored on the test of tacit knowledge, the lower they scored on the tests of crystallized abilities. This surprising result can be interpreted in various ways, but based on the ethnographic observations of the anthropologists on the team, we concluded that a plausible scenario takes into account the expectations of families for their children.

Many children drop out of school before graduation, for financial or other reasons, and many families in the village do not particularly value formal Western schooling. There is no reason they should, as the children of many families will for the most part spend their lives farming or engaged in other occupations that make little or no use of Western schooling. These families emphasize teaching their children the indigenous informal knowledge that will lead to successful adaptation in the environments in which they will really live. Children who spend their time learning the indigenous practical knowledge of the community generally do not invest themselves heavily in doing well in school, whereas children who do well in school generally do not invest themselves as heavily in learning the indigenous knowledge-hence the negative correlations.

The Kenya (Sternberg et al., 2001a,b), study suggests that the identification of a general factor of human intelligence may tell us more about how abilities interact with patterns of schooling and especially Western patterns of schooling than it does about the structure of human abilities. In Western schooling, children typically study a variety of subject matters from an early age and thus develop skills in a variety of skill areas. This kind of schooling prepares the children to take a test of intelligence, which typically measures skills in a variety of areas. Often, intelligence tests measure skills that children were expected to acquire a few years before taking the intelligence test. But as Rogoff (1990) and others have noted, this pattern of schooling is not universal and has not even been common for much of the history of humankind. Throughout history and in many places still, schooling, especially for boys, takes the form of apprenticeships in which children learn a craft from an early age. They learn what they will need to know in order to succeed in a trade, but not a lot more. They are not simultaneously engaged in tasks that require the development of the particular blend of skills measured by conventional intelligence tests. Hence, it is less likely that one would observe a general factor in their scores, much as the investigators discovered in Kenya. Some years back, Vernon (1971) pointed out that the axes of a factor analysis do not necessarily reveal a latent structure of the mind but rather represent a convenient way of characterizing 
the organization of mental abilities. Vernon believed that there was no one "right" orientation of axes, and indeed, mathematically, an infinite number of orientations of axes can be fit to any solution in an exploratory factor analysis. Vernon's point seems perhaps to have been forgotten or at least ignored by later theorists.

I have considered so far each of the aspects of intelligence separately. Next, I examine how they fare when assessed together.

\section{All Three Aspects of Intelligence Together}

Factor-Analytic Studies. Several separate factor-analytic studies support the internal validity of the theory of successful intelligence. In one study (Sternberg et al., 1999), we used the so-called Sternberg Triarchic Abilities Test (STAT-Sternberg, 1993) to investigate the internal validity of the theory. Three hundred twenty-six high school students, primarily from diverse parts of the United States, took the test, which comprised 12 subtests in all. There were four subtests each measuring analytical, creative, and practical abilities. For each type of ability, there were three multiple-choice tests and one essay test. The multiple-choice tests, in turn, involved, respectively, verbal, quantitative, and figural content. Consider the content of each test:

1. Analytical-Verbal: Figuring out meanings of neologisms (artificial words) from natural contexts. Students see a novel word embedded in a paragraph and have to infer its meaning from the context.

2. Analytical-Quantitative: Number series. Students have to say what number should come next in a series of numbers.

3. Analytical-Figural: Matrices. Students see a figural matrix with the lower right entry missing. They have to say which of the options fits into the missing space.

4. Practical-Verbal: Everyday reasoning. Students are presented with a set of everyday problems in the life of an adolescent and have to select the option that best solves each problem.

5. Practical-Quantitative: Everyday math. Students are presented with scenarios requiring the use of math in everyday life (e.g., buying tickets for a ballgame) and have to solve math problems based on the scenarios.

6. Practical-Figural: Route planning. Students are presented with a map of an area (e.g., an entertainment park) and have to answer questions about navigating effectively through the mapped area.

7. Creative-Verbal: Novel analogies. Students are presented with verbal analogies preceded by counterfactual premises (e.g., money falls 
off trees). They have to solve the analogies as though the counterfactual premises were true.

8. Creative-Quantitative: Novel number operations. Students are presented with rules for novel number operations, for example, "flix," which involves numerical manipulations that differ as a function of whether the first of two operands is greater than, equal to, or less than the second. Students have to use the novel number operations to solve presented math problems.

9. Creative-Figural: In each item, students are first presented with a figural series that involves one or more transformations; they then have to apply the rule of the series to a new figure with a different appearance, and complete the new series.

10. Analytical-Essay: This essay requires students to analyze the use of security guards in high schools: What are the advantages and disadvantages and how can these be weighed to make a recommendation?

11. Practical-Essay: Give three practical solutions to a problem you are currently having in your life.

12. Creative-Essay: Describe the ideal school.

Confirmatory factor analysis on the data was supportive of the triarchic theory of human intelligence, yielding separate and uncorrelated analytical, creative, and practical factors. The lack of correlation was due to the inclusion of essay as well as multiple-choice subtests. Although multiple-choice tests tended to correlate substantially with multiple-choice tests, their correlations with essay tests were much weaker. The multiple-choice analytical subtest loaded most highly on the analytical factor, but the essay creative and practical subtests loaded most highly on their respective factors. Thus, measurement of creative and practical abilities should, ideally, be accomplished with other kinds of testing instruments that complement multiplechoice instruments.

In another study, conducted with 3252 students in the United States, Finland, and Spain, we used the multiple-choice section of that STAT to compare five alternative models of intelligence, again via confirmatory factor analysis (Sternberg et al., 2001a). A model featuring a general factor of intelligence fit the data relatively poorly. The triarchic model, allowing for intercorrelation among the analytic, creative, and practical factors, provided the best fit to the data.

In a further study, we (Grigorenko and Sternberg, 2001) tested 511 Russian school children (ranging in age from 8 to 17 years) as well as 490 mothers and 328 fathers of these children. They used entirely distinct measures of analytical, creative, and practical intelligence. Consider, for 
example, the ability tests used for adults (similar tests were used for children) described next.

Fluid analytical intelligence was measured by two subtests of a test of nonverbal intelligence. The Test of g: Culture Fair, Level II (Cattell and Cattell, 1973) is a test of fluid intelligence designed to reduce, as much as possible, the influence of verbal comprehension, culture, and educational level, although no test eliminates such influences. In the first subtest, Series, individuals were presented with an incomplete, progressive series of figures. The participants' task was to select, from among the choices provided, the answer that best continued the series. In the Matrices subtest, the task was to complete the matrix presented at the left of each row.

The test of crystallized intelligence was adapted from existing traditional tests of analogies and synonyms/antonyms used in Russia. We used adaptations of Russian rather than American tests because the vocabulary used in Russia differs from that used in the United States. The first part of the test included 20 verbal analogies $(\mathrm{KR} 20=0.83)$. An example is circle-ball = square- ? (a) quadrangular, (b) figure, (c) rectangular, (d) solid, (e) cube. The second part included 30 pairs of words, and the participants' task was to specify whether the words in the pair were synonyms or antonyms $(\mathrm{KR} 20=0.74)$. Examples are latent-hidden, and systematicchaotic.

The measure of creative intelligence also comprised two parts. The first part asked the participants to describe the world through the eyes of insects. The second part asked participants to describe who might live and what might happen on a planet called "Priumliava." No additional information on the nature of the planet was specified. Each part of the test was scored in three different ways to yield three different scores. The first score was for originality (novelty); the second was for the amount of development in the plot (quality); and the third was for creative use of prior knowledge in these relatively novel kinds of tasks (sophistication). The measure of practical intelligence was self-report and also comprised two parts. The first part was designed as a 20 -item, self-report instrument, assessing practical skills in the social domain (e.g., effective and successful communication with other people), in the family domain (e.g., how to fix household items, how to run the family budget), and in the domain of effective resolution of sudden problems (e.g., organizing something that has become chaotic). The second part had four vignettes, based on themes that appeared in popular Russian magazines in the context of discussion of adaptive skills in the current society. The four themes were, respectively, how to maintain the value of one's savings, what to do when one makes a purchase and discovers that the item one has purchased is broken, how to locate medical assistance in a time of need, and how to manage a 
salary bonus one has received for outstanding work. Each vignette was accompanied by five choices and participants had to select the best one. Obviously, there is no one "right" answer in this type of situation. Hence Grigorenko and Sternberg used the most frequently chosen response as the keyed answer. To the extent that this response was suboptimal, this suboptimality would work against the researchers in subsequent analyses relating scores on this test to other predictor and criterion measures.

In this study, exploratory principal-component analysis for both children and adults yielded similar factor structures. Both varimax and oblimin rotations yielded clearcut analytical, creative, and practical factors for the tests. Thus, with a sample of a different nationality (Russian), a different set of tests, and a different method of analysis (exploratory rather than confirmatory analysis), there was again support for the theory of successful intelligence.

The analytical, creative, and practical tests the investigators employed were used to predict mental and physical health among the Russian adults. Mental health was measured by widely used paper-and-pencil tests of depression and anxiety, and physical health was measured by self-report. The best predictor of mental and physical health was the practicalintelligence measure. Analytical intelligence came second and creative intelligence came third. All three contributed to prediction, however. Thus, the researchers again concluded that a theory of intelligence encompassing all three elements provides better prediction of success in life than does a theory comprising just the analytical element.

In a recent study supported by the College Board (Sternberg and the Rainbow Project Team, 2002; Sternberg, the Rainbow Project Collaborators, and University of Michigan Business School Project Collaborators, 2004), we used an expanded set of tests on 1015 students at 15 different institutions (13 colleges and 2 high schools). Our goal was not to replace the SAT, but to devise tests that would supplement the SAT, measuring skills that this test does not measure. In addition to the multiple-choice STAT tests described earlier, we used three additional measures of creative skills and three of practical skills.

The three additional tests of creative skills were as follows:

1. Cartoons. Participants were given five cartoons purchased from the archives of the New Yorker, but with the caption removed. The participant's task was to choose three cartoons and to provide a caption for each cartoon. Two trained judges rated all the cartoons for cleverness, humor, and originality. A combined creativity score was formed by summing the individual ratings on each dimension. 
2. Written Stories. Participants were asked to write two stories, spending about $15 \mathrm{~min}$ on each, choosing from the following titles: "A Fifth Chance," "2983," "Beyond the Edge," "The Octopus's Sneakers," "It's Moving Backwards," and "Not Enough Time." A team of four judges was trained to rate the stories for originality, complexity, emotional evocativeness, and descriptiveness. These stories were based on work originally done to measure creativity (Sternberg and Lubart, 1995), which is described further later.

3. Oral Stories. Participants were presented with five sheets of paper, each containing a set of pictures linked by a common theme. For example, participants might receive a sheet of paper with images of a musical theme, a money theme, or a travel theme. The participant then chose one of the pages and was given $15 \mathrm{~min}$ to formulate a short story and dictate it into a cassette recorder. The dictation period was not to be more than 5 min long. The process was then repeated with another sheet of images so that each participant dictated a total of two oral stories. Six judges were trained to rate the stories for originality, complexity, emotional evocativeness, and descriptiveness.

The three additional tests of practical skills were as follows:

1. Everyday Situational Judgment Inventory (Movies). This videobased inventory presents participants with seven brief vignettes that capture problems encountered in general, everyday life, such as determining what to do when asked to write a letter of recommendation for someone you do not know particularly well.

2. Common Sense Questionnaire. This written inventory presents participants with 15 vignettes that capture problems encountered in general business-related situations, such as managing tedious tasks or handling a competitive work situation.

3. College Life Questionnaire. This written inventory presents participants with 15 vignettes that capture problems encountered in general college-related situations, such as handling trips to the bursar's office or dealing with a difficult roommate.

We found that our tests significantly and substantially improved upon the validity of the SAT for predicting first-year college grades (Sternberg and the Rainbow Project Collaborators, 2005). The test also improved equity: Using the expanded test to admit a class would result in greater ethnic diversity than would using just the SAT or just the SAT and grade-point average. This expanded test is now going into Phase-2 piloting, where it will be tried out on a larger sample of individuals. 
Instructional Studies. Instructional studies are a further means of testing the theory. We have used instruction both in cognitive skills, in general (Sternberg, 1987a; Sternberg and Williams, 1996; Williams et al., 2002), and in academic skills, in particular (Sternberg et al., 1998a,b).

1. Cognitive skills. The kinds of analytical, creative, and practical abilities discussed in this article are not fixed, but rather, modifiable.

Analytical skills can be taught. For example, in one study, I (Sternberg, 1987a) tested whether it is possible to teach people better to decontextualize meanings of unknown words presented in context. In one study, I gave 81 participants a pretest on their ability to decontextualize word meanings. Then the participants were divided into five conditions, two of which were control conditions that lacked formal instruction. In one condition, participants were not given any instructional treatment. They were merely asked later to take a post-test. In a second condition, they were given practice as an instructional condition, but there was no formal instruction, per se. In a third condition, they were taught knowledge-acquisition component processes that could be used to decontextualize word meanings. In a fourth condition, they were taught to use context cues. In a fifth condition, they were taught to use mediating variables. Participants in all three of the theory-based formal-instructional conditions outperformed participants in the two control conditions, whose performance did not differ. In other words, theory-based instruction was better than no instruction at all or just practice without formal instruction.

Creative-thinking skills also can be taught and a program has been devised for teaching them (Sternberg and Williams, 1996; see also Sternberg and Grigorenko, 2000). In some relevant work, the investigators divided 86 gifted and nongifted fourth-grade children into experimental and control groups. All children took pretests on insightful thinking. Then some of the children received their regular school instruction, whereas others received instruction on insight skills. After instruction, all children took a post-test on insight skills. Results indicated that children taught how to solve the insight problems using knowledge-acquisition components gained more from pretest to post-test than did students who were not so taught (Davidson and Sternberg, 1984).

Practical-intelligence skills also can be taught. We developed a program for teaching practical intellectual skills, aimed at middle school students, that explicitly teaches students "practical intelligence for school" in the contexts of doing homework, taking tests, 
reading, and writing (Gardner et al., 1994; Williams et al., 1996, 2002). We evaluated the program in a variety of settings (Gardner et al., 1994; Sternberg et al., 1990) and found that students taught via the program outperformed students in control groups that did not receive the instruction.

Individuals' use of practical intelligence can be to their own gain in addition to or instead of the gain of others. People can be practically intelligent for themselves at the expense of others. It is for this reason that wisdom needs to be studied in its own right in addition to practical or even successful intelligence (Baltes and Staudinger, 2000; Sternberg, 1998b).

In sum, practical intelligence, like analytical intelligence, is an important antecedent of life success. Because measures of practical intelligence predict everyday behavior at about the same level as measures of analytical intelligence (and sometimes even better), the sophisticated use of such tests could double the explained variance in various kinds of criteria of success. Using measures of creative intelligence as well might increase prediction still more. Thus, tests based on the construct of successful intelligence might lead to new and higher levels of prediction. At the same time, expansions of conventional tests that stay within the conventional framework of analytical tests based on standard psychometric models do not seem likely to expand greatly our predictive capabilities (Schmidt and Hunter, 1998).

I view intelligence as a form of developing expertise (Sternberg, 1998a, 1998d, 1999a, 2003a). Indeed, some of the tests we use may seem more like tests of achievement or of developing expertise (see Ericsson, 1996; Howe et al., 1998) than of intelligence. But it can be argued that intelligence is itself a form of developing expertisethat there is no clearcut distinction between the two constructs (Sternberg, 1998a, 1999a). Indeed, all measures of intelligence, one might argue, measure a form of developing expertise.

An example of how tests of intelligence measure developing expertise emanates from work we have done in Tanzania. A study done in Tanzania (see Sternberg and Grigorenko, 1997; Sternberg et al., 2002a) points out the risks of giving tests, scoring them, and interpreting the results as measures of some latent intellectual ability or abilities. We administered to 358 school children between the ages of 11 and 13 years near Bagamoyo, Tanzania, tests including a form-board classification test, a linear syllogisms test, and a Twenty Questions Test, which measure the kinds of skills required on conventional tests of intelligence. Of course, we obtained scores that 
they could analyze and evaluate, ranking the children in terms of their supposed general or other abilities. However, we administered the tests dynamically rather than statically (Brown and Ferrara, 1985; Budoff, 1968; Day et al., 1997; Feuerstein, 1979; Grigorenko and Sternberg, 1998; Guthke, 1993; Haywood and Tzuriel, 1992; Lidz, 1987, 1991; Sternberg and Grigorenko, 2002a; Tzuriel, 1995; Vygotsky, 1978). Dynamic testing is like conventional static testing in that individuals are tested and inferences about their abilities made. But dynamic tests differ in that children are given some kind of feedback in order to help them improve their scores. Vygotsky (1978) suggested that the children's ability to profit from the guided instruction received during the testing session could serve as a measure of children's zone of proximal development (ZPD), or the difference between their developed abilities and their latent capacities. In other words, testing and instruction are treated as being of one piece rather than as being distinct processes.

This integration makes sense in terms of traditional definitions of intelligence as the ability to learn ("Intelligence and its measurement," 1921; Sternberg and Detterman, 1986). What a dynamic test does is directly measure processes of learning in the context of testing rather than measuring these processes indirectly as the product of past learning. Such measurement is especially important when not all children have had equal opportunities to learn in the past.

In our assessments, children were first given the ability tests. In an experimental group, they then were given a brief period of instruction in which they were able to learn skills that would potentially enable them to improve their scores. In a control group, they were not given this intervention. Then all students were tested again. Because the instruction for each test lasted only about 5-10 min, dramatic gains were not expected. Yet, on average, the gains were statistically significant in the experimental group, and statistically greater than in the control group. In the control group, pretest and post-test scores correlated at the 0.8 level. In the experimental group, however, scores on the pretest showed only weak although significant correlations with scores on the post-test. These correlations, at about the 0.3 level, suggested that when tests are administered statically to children in developing countries, they may be rather unstabl and easily subject to influences of training. The reason could be that the children are not accustomed to taking Western-style tests, and so profit quickly even from small amounts of instruction as to what is expected from them. Of course, the more important question is not whether the scores changed or even 
correlated with each other, but rather how they correlated with other cognitive measures. In other words, which test was a better predictor of transfer to other cognitive performance, the pretest score or the post-test score? The post-test score was the better predictor.

2. Academic skills. In a first set of studies, researchers explored the question of whether conventional education in school systematically discriminates against children with creative and practical strengths (Sternberg and Clinkenbeard, 1995; Sternberg et al., 1996, 1999). Motivating this work was the belief that the systems in most schools strongly tend to favor children with strengths in memory and analytical abilities. However, schools can be unbalanced in other directions as well. One school Elena Grigorenko and I visited in Russia in 2000 placed a heavy emphasis on the development of creative abilities - much more so than on the development of analytical and practical abilities. While on this trip, we were told of yet another school-catering to the children of Russian businessman-that strongly emphasized practical abilities, and in which children who were not practically oriented were told that, eventually, they would be working for their classmates who were practically oriented.

The investigators used the Sternberg Triarchic Abilities Test, as described earlier, in some of our instructional work. The test was administered to 326 children around the United States and in some other countries who were identified by their schools as gifted by any standard whatsoever. Children were selected for a summer program in (college-level) psychology if they fell into one of five ability groupings: high analytical, high creative, high practical, high balanced (high in all three abilities), or low balanced (low in all three abilities). Selected students who came to Yale University were then divided into four instructional groups. Students in all four instructional groups used the same introductory-psychology textbook (a preliminary version of Sternberg [1995]) and listened to the same psychology lectures. What differed among them was the type of afternoon discussion section to which they were assigned. They were assigned to an instructional condition that emphasized either memory, analytical, creative, or practical instruction. For example, in the memory condition, they might be asked to describe the main tenets of a major theory of depression. In the analytical condition, they might be asked to compare and contrast two theories of depression. In the creative condition, they might be asked to formulate their own theory of depression. In the practical condition, they might be asked how they could use 
what they had learned about depression to help a friend who was depressed.

Students in all four instructional conditions were evaluated in terms of their performance on homework, a midterm exam, a final exam, and an independent project. Each type of work was evaluated for memory, analytical, creative, and practical quality. Thus, all students were evaluated in exactly the same way. Results suggested the utility of the theory of successful intelligence. This utility showed itself in several ways.

First, we observed when the students arrived at Yale University that the students in the high creative and high practical groups were much more diverse in terms of racial, ethnic, socioeconomic, and educational backgrounds than were the students in the high analytical group, suggesting that correlations of measured intelligence with status variables such as these may be reduced by using a broader conception of intelligence. Thus, the kinds of students identified as strong differed in terms of populations from which they were drawn in comparison with students identified as strong solely by analytical measures. More importantly, just by expanding the range of abilities measured, the investigators discovered intellectual strengths that might not have been apparent through a conventional test.

Second, we found that all three ability tests-analytical, creative, and practical-predicted course performance. When multiple-regression analysis was used, at least two of these ability measures contributed significantly to the prediction of each of the measures of achievement. Perhaps as a reflection of the difficulty of deemphasizing the analytical way of teaching, one of the significant predictors was always the analytical score. (However, in a replication of our study with low-income African-American students from New York, Deborah Coates of the City University of New York found a different pattern of results. Her data indicated that the practical tests were better predictors of course performance than were the analytical measures, suggesting that what ability test predicts what criterion depends on population as well as mode of teaching.)

Third, and most importantly, there was an aptitude-treatment interaction whereby students who were placed in instructional conditions that better matched their pattern of abilities outperformed students who were mismatched. In other words, when students are taught in a way that fits how they think, they do better in school. Children with creative and practical abilities, who are almost never taught or assessed in a way that matches their pattern of abilities, may be at a disadvantage in course after course, year after year. 
A follow-up study (Sternberg et al., 1998a,b) examined learning of social studies and science by third-graders and eighth-graders. The 225 third-graders were students in a low-income neighborhood in Raleigh, North Carolina. The 142 eighth-graders were students who were largely from middle- to upper-middle class homes studying in Baltimore, Maryland, and Fresno, California. In this study, students were assigned to one of three instructional conditions. In the first condition, they were taught the course that basically they would have learned had there been no intervention. The emphasis in the course was on memory. In a second condition, students were taught in a way that emphasized critical (analytical) thinking. In the third condition, they were taught in a way that emphasized analytical, creative, and practical thinking. All students' performance was assessed for memory learning (through multiple-choice assessments) as well as for analytical, creative, and practical learning (through performance assessments).

As expected, students in the successful-intelligence (analytical, creative, practical) condition outperformed the other students in terms of the performance assessments. One could argue that this result merely reflected the way they were taught. Nevertheless, the result suggested that teaching for these kinds of thinking succeeded. More important, however, was the result that children in the successful-intelligence condition outperformed the other children even on the multiple-choice memory tests. In other words, to the extent that one's goal is just to maximize children's memory for information, teaching for successful intelligence is still superior. It enables children to capitalize on their strengths and to correct or to compensate for their weaknesses, and it allows children to encode material in a variety of interesting ways.

We have now extended these results to reading curricula at the middle school and the high school level (Grigorenko et al., 2002). In a study of 871 middle school students and 432 high school students, we taught reading either triarchically or through the regular curriculum. At the middle school level, reading was taught explicitly. At the high school level, reading was infused into instruction in mathematics, physical sciences, social sciences, English, history, foreign languages, and the arts. In all settings, students who were taught triarchically substantially outperformed students who were taught in standard ways.

Thus, the results of three sets of studies suggest that the theory of successful intelligence is valid as a whole. Moreover, the results 
suggest that the theory can make a difference not only in laboratory tests but in school classrooms and even the everyday life of adults as well.

\section{Creativity}

\section{The Nature of Creativity}

Creativity is not an attribute limited to the historic "greats"- the Darwins, the Picassos, the Hemingways. Rather, it is something anyone can use. To a large extent, creativity is a decision.

According to the investment theory of creativity, creative leaders are like good investors: They buy low and sell high (Sternberg, 2003b; Sternberg and Lubart, 1995, 1996). Whereas investors do so in the world of finance, creative leaders do so in the world of ideas. Creative leaders generate ideas that are like undervalued stocks (stocks with a low price-to-earnings ratio), and both the stocks and the ideas are generally rejected by the public. When creative ideas are proposed, they often are viewed as bizarre, useless, and even foolish, and are summarily rejected. The person proposing them often is regarded with suspicion and perhaps even with disdain and derision. This is one of many reasons that it is so hard to change schools and school systems: People are often suspicious of, rather than welcoming, change.

Creative ideas are both novel and valuable. They potentially have impact (Sternberg, 2003a). But, they are often rejected because the creative leader stands up to vested interests and defies the crowd. The crowd does not maliciously or willfully reject creative notions. Rather, it does not realize, and often does not want to realize, that the proposed idea represents a valid and advanced way of thinking. Society generally perceives opposition to the status quo as annoying, offensive, and reason enough to ignore innovative ideas.

Evidence abounds that creative ideas are often rejected (Gardner, 1993a; Sternberg, 2003b; Sternberg and Lubart, 1995). Initial reviews of major works of literature and art are often negative. Toni Morrison's Tar Baby received negative reviews when it was first published, as did Sylvia Plath's The Bell Jar. The first exhibition in Munich of the work of Norwegian painter Edvard Munch opened and closed the same day because of the strong negative response from the critics. Some of the greatest scientific papers have been rejected not just by one journal but even by several journals before being published. For example, John Garcia, a distinguished biopsychologist, was immediately denounced when he first proposed that a form 
of learning called classical conditioning could be produced in a single trial of learning (Garcia and Koelling, 1966).

From the investment view, then, the creative leader buys low by presenting a unique idea and then attempting to convince other people of its value. After convincing others that the idea is valuable, which increases the perceived value of the investment, the creative person sells high by leaving the idea to others and moving on to another idea. Leaders typically want others to embrace their ideas, but immediate universal applause for an idea usually indicates that it is not particularly creative. Many educators spend their lives feeling frustrated, waiting for the acceptance of their ideas that never is forthcoming.

Creativity is as much a decision about and an attitude toward life as it is a matter of ability. Creativity is often obvious in young children, but it is harder to find in older children and adults because their creative potential has been suppressed by a society that encourages intellectual conformity.

Creative work requires applying and balancing the three intellectual abilities-creative, analytic, and practical-all of which can be developed (Sternberg, 1985a; Sternberg and Lubart, 1995; Sternberg and O'Hara, 1999; Sternberg and Williams, 1996). Creative ability is used to generate ideas. Everyone, even the most creative person, has better and worse ideas. Without well-developed analytic ability, the creative thinker is as likely to pursue bad ideas as to pursue good ones. The creative individual uses analytic ability to work out the implications of a creative idea and to test it. Practical ability is the ability to translate theory into practice and abstract ideas into practical accomplishments. An implication of the investment theory of creativity is that good ideas do not sell themselves. The creative person uses practical ability to convince other people that an idea is valuable. For example, every organization has a set of ideas that dictate how things, or at least some things, should be done. When an individual proposes a new procedure, they must sell it by convincing others that it is better than the old one. Practical ability is also used to recognize ideas that have a potential audience.

Creativity requires analytic and practical as well as creative skills. Leaders may fail to be creative because they lack any of the skills. The leader who is only synthetic may come up with innovative ideas, but cannot recognize or sell them. The leader who is only analytic may be an excellent critic of other people's ideas, but is not likely to generate creative ideas. The leader who is only practical may be an excellent salesperson, but is as likely to promote ideas or products of little or no value as to promote genuinely creative ideas. 


\section{Attributes Leading to Creativity}

What kinds of attributes should one look for in leaders in order to assess their creativity?

1. Redefining problems. Redefining a problem means taking a problem and turning it on its head. Many times in life, individuals have a problem and they just do not see how to solve it. They are stuck in a box. Redefining a problem essentially means extricating oneself from the box. This process is the synthetic part of creative thinking.

The educational leader encounters many kinds of novel situations that resist easy definition in terms of past experience. The more flexible the individual is in redefining these situations so that they make sense to him or her, the more likely the individual is to succeed. Flexible definition and redefinition of problems, thus, is essential to creativity (Davidson and Sternberg, 1984; Getzels and Csikszentmihalyi, 1976; Sternberg, 1985a). Getzels and Csikszentmihalyi's (1976) seminal research on problem finding showed that art students who produced highly original still-life drawings spent longer periods of time formulating their compositions than less creative peers.

2. Questioning and analyzing assumptions. Often one does not realize the nature of the assumptions one has because these assumptions are widely shared. Creative people question assumptions and eventually lead others to do the same. Questioning assumptions is part of the analytical thinking involved in creativity. When Copernicus suggested that Earth revolves around the sun, the suggestion was viewed as preposterous because everyone could see that the sun revolves around Earth. Galileo's ideas, including the relative rates of falling objects, caused him to be banned as a heretic.

Sometimes it is not until many years later that society realizes the limitations or errors of their assumptions and the value of the creative person's thoughts. The impetus of those who question assumptions allows for cultural, technological, and other forms of advancement.

Schools in particular, and society in general, tend to make a pedagogical mistake by emphasizing the answering and not the asking of questions (Sternberg, 1994). The good student is perceived as the one who rapidly furnishes the right answers. The expert in a field thus becomes the extension of the expert student - the one who knows and can recite a lot of information. As John Dewey (1933) recognized, how one thinks is often more important than what one 
thinks. Schools need to teach students how to ask the right questions (questions that are good, thought-provoking, and interesting) and lessen the emphasis on rote learning. Institutions perhaps do not wish to identify as educational leaders those who merely are experts in spitting back what others have previously said.

3. Realizing that creative ideas do not sell themselves. Everyone would like to assume that their wonderful, creative ideas will sell themselves. But as Galileo, Edvard Munch, Toni Morrison, Sylvia Plath, and many others have discovered, they do not. On the contrary, creative ideas are usually viewed with suspicion and distrust (see essays in Sternberg, 1998c, 2003b). Moreover, those who propose such ideas may be viewed with suspicion and distrust as well. Because people are comfortable with the ways they already think, and because they probably have a vested interest in their existing way of thinking, it is difficult to dislodge them from their current way of thinking. Superintendents often must spend more time selling their ideas than coming up with them.

4. Recognizing that knowledge is a double-edged sword. On the one hand, one cannot be creative without knowledge. Quite simply, one cannot go beyond the existing state of knowledge if one does not know what that state is. Many students have ideas that are creative with respect to themselves, but not with respect to the field because others have had the same ideas before. Those with a greater knowledge base can be creative in ways that those who are still learning about the basics of the field cannot be.

At the same time, those who have an expert level of knowledge can experience tunnel vision, narrow thinking, and entrenchment. Experts can become so stuck in a way of thinking that they become unable to extricate themselves from it (Adelson, 1984; Frensch and Sternberg, 1989; Sternberg and Lubart, 1995). For example, Frensch and Sternberg (1989) found experts more susceptible than novices to set effects in bridge when the basic rules of the game were played. Learning must be a lifelong process, not one that terminates when a person achieves some measure of recognition. When a person believes that he or she knows everything there is to know, he or she is unlikely to ever show truly meaningful creativity again.

The upshot of this is that the teaching-learning process is a twoway process. We, as teachers, have as much to learn from our students as they have to learn from us. We have knowledge they do not have, but they have flexibility we do not have-precisely because they do not know as much as we do. By learning from, as well as teaching to, one's students, one opens up channels for creativity 
that otherwise would remain closed. The educational leader needs to use knowledge to move beyond where things are, rather than to replicate what others have already done or to get stuck in old ways of thinking that no longer are serving a constructive purpose.

5. Willingness to surmount obstacles. Buying low and selling high means defying the crowd. And people who defy the crowd-people who think creatively-almost inevitably encounter resistance. The question is not whether one will encounter obstacles; that obstacles will be encountered is a fact. The question is whether the creative leader has the fortitude to persevere (Golann, 1962; Roe, 1952). I have often wondered why so many people start off their careers doing creative work and then vanish from the radar screen. Here is at least one reason why: Sooner or later, they decide that being creative is not worth the resistance and punishment. The truly creative leaders pay the short-term price because they recognize that they can make a difference in the long term. But often it is a long while before the value of creative ideas is recognized and appreciated.

Creative individuals encounter many obstacles in their lives. Some of them have led "charmed" lives. But sooner or later, the obstacles start to present themselves. The ones who go on to greatness are those who are prepared to surmount rather than succumb to these obstacles.

6. Willingness to take sensible risks. When creative leaders defy the crowd by buying low and selling high, they take risks in much the same way as do people who invest. Some such investments simply may not pan out. Moreover, defying the crowd means risking the crowd's wrath. But there are levels of sensibility to keep in mind when defying the crowd. Creative leaders take sensible risks and produce ideas that others ultimately admire and respect as trendsetting (Glover, 1977; McClelland et al., 1953). In taking these risks, creative people sometimes make mistakes, fail, and fall flat on their faces.

Nearly every major discovery or invention entailed some risk. When a movie theater was the only place to see a movie, someone created the idea of the home video machine. Skeptics questioned if anyone would want to see videos on a small screen. Another initially risky idea was the home computer. Many wondered if anyone would have enough use for a home computer to justify the cost. These ideas were once risks that are now ingrained in our society.

Willingness to take risks is especially important for creative leaders. Many of them got to where they are by not taking risks. They played the academic game with consummate gamesmanship, 
doing what needed to be done and playing it safe so that they would not get "burned." But there is a transition in the life of every great leader. He or she needs to start taking risks. It is important, therefore, to select people who are willing to risk.

7. Tolerance of ambiguity. People often like things to be in black and white. They like to think that a country is good or bad (ally or enemy) or that a given idea in education works or does not work. The problem is that there are a lot of grays in creative work. Artists working on new paintings and writers working on new books often report feeling scattered and unsure in their thoughts. They often need to figure out whether they are even on the right track. Scientists often are not sure whether the theory they have developed is exactly correct. These creative thinkers need to tolerate the ambiguity and uncertainty until they get the idea just right (Barron and Harrington, 1981; Golann, 1962).

A creative idea tends to come in bits and pieces and develops over time. However, the period in which the idea is developing tends to be uncomfortable, as Darwin found in formulating his theory of evolution over a long period of time. Without time or the ability to tolerate ambiguity, many may jump to a less than optimal solution. Creative leaders often undertake major projects in their early years. They should be individuals who are willing to tolerate ambiguity long enough to make these projects not just good, but great.

8. Willingness to grow. Many people have one or two creative ideas early on, but then become afraid to have any more. They may be afraid that their next idea will not be as good as their last one, or that they will embarrass themselves if the new idea does not pan out. Or they may have acquired an investment in an idea and not want to give it up. Leaders who are creative throughout their lives continue to grow and recognize that learning is life-long (Sternberg and Lubart, 1995).

9. Self-efficacy. People often reach a point where they feel as if no one believes in them or values or even appreciates what they are doing. Because creative work often does not get a warm reception, it is important that the creative leaders believe in the value of what they are doing. This is not to say that individuals should believe that every idea they have is a good idea. Rather, individuals need to believe that, ultimately, they have the ability to make a difference. In the course of their studies, creative individuals will sometimes doubt themselves. To succeed in life, one has to believe not in each and every thing one does, but in one's ability to get done what needs to get 
done, and to recover from the inevitable setbacks that life throws one's way (Bandura, 1997).

10. Finding what one loves to do. Teachers must help students find what excites them to unleash their students' best creative performances. Teachers need to remember that this may not be what really excites them. Leaders who truly excel creatively in a pursuit, whether vocational or avocational, almost always genuinely love what they do. Certainly, the most creative leaders are intrinsically motivated in their work (Amabile, 1983, 1996; Crutchfield, 1962; Golann, 1962; Rogers, 1954). Less creative people often pick a career for the money or prestige and are bored with or loathe their career. Most often, these people do not do work that makes a difference in their field.

One often meets students who are pursuing a certain field not because it is what they want to do, but because it is what their parents or other authority figures expect them to do. One may feel sorry for such students, knowing that although they may do good work in that field, they almost certainly will not do great work. It is hard for people to do great work in a field that simply does not interest them.

Identification committees should select those students who genuinely love what they do and wish to keep doing it, not because it brings them extrinsic rewards, but because they feel a calling to do it. The people who feel such a calling are the ones who later can make a true difference.

11. Willingness to delay gratification. Part of being creative means being able to work on a project or task for a long time without immediate or interim rewards. Students must learn that rewards are not always immediate and that there are benefits to delaying gratification (Mischel et al., 1989). The fact of the matter is that, in the short term, people are often ignored when they do creative work or even punished for doing it.

Hard work often does not bring immediate rewards. Students do not immediately become expert baseball players, dancers, musicians, or sculptors. And the reward of becoming an expert can seem far away. Students often succumb to the temptations of the moment, such as watching television or playing video games. The people who make the most of their abilities are those who wait for a reward and recognize that few serious challenges can be met in a moment.

The short-term focus of most school assignments does little to teach children the value of delaying gratification. Long-term projects are clearly superior in meeting this goal, but it is difficult 
for teachers to assign home projects if they are not confident of parental involvement and support. By working on a task for many weeks or months, students learn the value of making incremental efforts for long-term gains.

Because much of schooling is about short-term rewards, many of the candidates for selective programs will not truly have learned the importance of delaying gratification. Yet it is a lesson they need to learn because the great contributions to the world are rarely made quickly.

12. Courage. Defying the crowd takes, above all, courage. Those who do not have courage of their convictions may be many things-they will not be creative. A creative leader can be many things. If he or she is not courageous, the other things may not matter (Amabile, 1983; Barron and Harrington, 1981; Dellas and Gaier, 1970; Golann, 1962; MacKinnon, 1962, 1965).

\section{Kinds of Creative Leadership}

Theorists of creativity and related topics have recognized that there are different types of creative leadership (see reviews in Ochse, 1990; Sternberg, 1988; Weisberg, 1993). For example, Kuhn (1970) distinguished between normal and revolutionary science. Normal science expands upon an already existing paradigm of scientific research, whereas revolutionary science proposes a new paradigm. Revolutionary leading thinkers have included Newton and Einstein in the field of physics, Darwin and Wallace in the field of biology, Braque and Picasso in the field of art, and Freud and Wundt in the field of psychology. Darwin's contribution is particularly well analyzed by Gruber (1981).

Gardner (1993b, 1994) also described different types of creative contributions individuals can make. They include (a) the solution of a welldefined problem, (b) the development of an encompassing theory, (c) the creation of a "frozen work," (d) the performance of a ritualized work, and (e) a "high-stakes" performance. Other bases for distinguishing among types of creative contributions also exist. For example, psychoeconomic models such as those of Rubenson and Runco (1992) and Sternberg and Lubart $(1991,1995,1996)$ can distinguish different types of contributions in terms of the parameters of the models. In the Sternberg-Lubart model, contributions might differ in the extent to which they "defy the crowd" or in the extent to which they redefine how a field perceives a set of problems. Simonton's (1997) model of creativity also proposes parameters of creativity, and contributions might be seen as differing in terms of the extent to 
which they vary from other contributions and the extent to which they are selected for recognition by a field of endeavor (see also Campbell, 1960; Perkins, 1995; Simonton, 1997). But in no case were these models intended explicitly to distinguish among types of creative contributions. Rather, the models can be extrapolated to suggest how different creators might differ in their contributions in terms of the parameters that are proposed to make the contributors creative.

A view that is more likely to distinguish among types of creative leadership was proposed by Gough and Woodworth (1960), who discussed stylistic variations among professional research scientists. The styles include zealots, initiators, diagnosticians, scholars, artificers, estheticians, and methodologists. For example, a zealot proposes a cause and then becomes strongly identified with that cause, sometimes with only minimal empirical support for the arguments behind the cause. A methodologist concentrates on and takes great care with the methodology of his or her contributions and perhaps with the innovation inhering in the methodology, possibly at the expense of paying attention to the substantive contribution.

Maslow (1967) distinguished more generally between two types of creativity, which he referred to as primary and secondary. Primary creativity is the kind of creativity a person uses to become self-actualized-to find fulfillment in one's life. Secondary creativity is the kind of creativity with which scholars in the field are more familiar-the kind that leads to creative achievements of the kind typically recognized by a field.

Disagreements among scholars in the field of creativity also may reflect different kinds of creative leadership. Ward et al. (1999) noted three such apparent disagreements and how the disagreements may reflect differences in kinds of creativity rather than in what "truly" underlies creativity. One apparent disagreement is regarding goal-oriented versus exploratory creativity. Ward and his colleagues noted that there is evidence to favor the roles of focusing (Bowers et al., 1990; Kaplan and Simon, 1990) and of exploratory thinking (Bransford and Stein, 1984; Getzels and Csikszentmihalyi, 1976) on creative thinking. It may be, however, that both kinds of thinking can lead to creative work of different kinds. A second distinction made by Ward and his colleagues is between domain-specific (Clement, 1989; Langley et al., 1987; Perkins, 1981; Weisberg, 1986) and universal (Finke, 1990, 1995; Guilford, 1968; Koestler, 1964) creativity skills, although both kinds of skills may be relevant to creativity. They suggested, for example, that efficient exploration of a preinventive structure depends on knowledge and experience, but that that general methods may be relevant in designing a new form of transportation. Finally, Ward and his colleagues distinguished between unstructured (Bateson, 1979; Findlay and Lumsden, 1988; Johnson-Laird, 1988) and structured or systematic 
(Perkins, 1981; Ward, 1994; Weisberg, 1986) creativity. Unstructured creativity suggests that randomness, or perhaps blind variation in the generation of ideas, plays a major role in creativity (see, e.g., Cziko, 1998; Simonton, 1998), whereas structured creativity suggests that some kind of system is highly involved in the generation of ideas (see, e.g., Sternberg, 1999b). Again, Ward and his colleagues saw structure and lack of structure as complementary rather than contradictory. Indeed, different biological mechanisms - such as in levels or types of cortical activation-may underlie different types of creativity (Martindale, 1999).

Here, I propose that there are three basic types of creative educational leadership (Sternberg, 1999b; Sternberg et al., 2002b, 2003). One type accepts current paradigms. This type includes replication, redefinition, forward incrementation, and advance forward incrementation. A second type rejects current paradigms. It includes redirection, reconstruction/redirection, and reinitiation. And a third type synthesizes current paradigms. It includes simply synthesis. Consider each kind.

\section{Types of Creative Leadership that Accept Current Paradigms}

Replication. This type of creative leadership is a limiting (minimally creative) case. It is an attempt to show that a field or organization is in the right place at the right time. The leader therefore attempts to maintain it in that place. The propulsion keeps the organization where it is rather than moving it. The view of the leader is that the organization is where it needs to be. The leader's role is to keep it there. This type of creativity is represented by stationary motion, as of a wheel that is moving but staying in place. The replicative leader metaphorically pedals in place, as with a stationary bicycle.

Organizations tend to choose replicative leaders when the organization is succeeding and the goal of those seeking the new leader is to maintain the perceived status, and perhaps, preeminence, of the organization. The greatest threat to the organization is likely to be perceived to be loss of current status, not failure to gain new status. The organization is seen as one that does not need to change or appear to change (cf., Sternberg, 2002). Organizations with highly successful product or service lines may seek replicative leaders who will maintain the standing of these lines. Organizations that have had a highly successful and possibly charismatic leader for some time may be happy to seek a leader who can, to the extent possible, replicate the success of the previous leader. Schools that have been successful in the past by following a certain formula may seek leaders who are like the leaders of the past. 
Replicative leadership is likely to be most successful during time periods of relative stability, both in terms of consumer demands and in terms of competitive threats. In times of flux, the kind of leader that worked before may not work again, and the organization may lose preeminence by selecting a leader like the last one.

Redefinition. This type of creative leadership is an attempt to show that a field or organization is in the right place, but not for the reason(s) that others, including previous leaders, think it is. The current status of the organization thus is seen from a different point of view. The propulsion leads to circular motion, such that the creative leadership directs back to where the organization is, but as viewed in a different way. Metaphorically, this type of leadership is like riding a bicycle in a circle, so that one returns to where one is but sees it from a different vantage point. Redefiners are chosen by organizations because they can maintain a status quo but appear to justify that status quo in terms most palatable to followers. A school district might choose a redefiner as a superintendent if it wants someone who appears to change things, but who does not really change anything other than the image.

Forward Incrementation. This type of creative leadership is an attempt to lead a field or an organization forward in the direction it already is going. The propulsion leads to forward motion.

Most educational leadership is probably forward incrementation. In such leadership, one takes the helm with the idea of advancing the leadership program of whomever one has succeeded. The promise is of progress through continuity. Creativity through forward incrementation is probably the kind that is most easily recognized and appreciated as creativity. Because it extends existing notions, it is seen as creative. Because it does not threaten the assumptions of such notions, it is not rejected as useless or even harmful. Forward incrementation is like riding a bike forward in the direction it has been going at a comfortable rate of speed.

Forward incrementations tend to be successful when times are changing in relatively predictable and incremental ways. The times thus match the leadership strategy, whether in terms of leadership of people or leadership of products. When times change unpredictably, leaders may find that their strategy no longer works. For example, many Internet start-ups in the late 1990s were simple forward incrementations of other such businesses. Small variants in products or even image seemed to be enough to generate investment capital, if not to start a successful business. But when the dot-com market crashed, many of the start-ups went with it. There was no longer any investment capital to be had for just another variant of what already existed, and there was insufficient customer base to support the businesses. Many school leaders are forward incrementers. They make changes 
but ones that are small, carefully planned, and consistent with the direction things already are going in the school.

Advance Forward Incrementation. This type of creative leadership is an attempt to move an organization forward in the direction it is already going, but by moving beyond where others are ready for it to go. The propulsion leads to forward motion that is accelerated beyond the expected rate of forward progression.

Advance forward incrementations usually are not successful at the time they are attempted because followers in fields and organizations are not ready to go where the leader wants to lead. Or significant portions of followers may not wish to go to that point, in which case they form an organized and sometimes successful source of resistance. Advance forward incrementers are often not appreciated because they want to move things ahead too fast. As a principal, the school leader may find him or herself wanting to lead teachers to places they are not ready to go. Advance forward incrementation is like riding a bike forward at a rapid rate so that people may become afraid that the bike will run them over or otherwise crash.

\section{Types of Creative Leadership That Reject Current Paradigms}

Redirection. This type of creative leadership is an attempt to redirect an organization, field, or product line from where it is headed toward a different direction. The propulsion thus leads to motion in a direction that diverges from the way the organization is currently moving.

Redirections can change a field in unpredictable ways. For example, computers were originally viewed as rapid serial information processors. Artificial-intelligence research tried to create expert programs by creating ever more rapid and powerful rapid serial processors. But then it was realized that computer learning might better occur through massive parallel distributed processing. Today many computer programs use such a model and are able to achieve higher levels of expertise than was possible through the serial information-processing model. School reformers who are redirectors generally try to change the direction in which a school is moving. Whether they succeed depends as much on the structure of the bureaucracy in which they are working as it does on their own leadership qualities. In redirection, one metaphorically continues to ride one's bike, but in a totally new direction that is different from the previous one.

Reconstruction/redirection. This type of creative leadership is an attempt to move a field or an organization or a product line back to where it once was (a reconstruction of the past) so that it may move onward from that point, but in a new direction. The propulsion thus leads to motion that is backward and then redirective from an earlier point in time. Current 
attempts to move schools back to the "three R's" are, to some extent, reconstructive redirections. In reconstruction/redirection, one metaphorically rides one's bicycle backward to a point one previously reached, and sets off in a new direction from there.

Reinitiation. This type of creative leadership is an attempt to move a field, organization, or product line to a different, not yet reached starting point and then to move from that point. The propulsion is thus from a new starting point in a direction that is different from that the field, organization, or product line previously has pursued. Reinitiators are leaders who try to move an educational system in a totally different direction and from a starting point other than that which the school is at. In reinitiation, one metaphorically picks up one's bike, takes it to a new location, and sets off in a new direction from one's new starting point.

\section{A Type of Creative Leadership that Integrates Current Paradigms}

Synthesis In this type of creative leadership, the creator integrates two ideas that previously were seen as unrelated or even as opposed. What formerly were viewed as distinct ideas now are viewed as related and capable of being unified. Integration is a key means by which progress is attained in the sciences. It represents neither an acceptance nor a rejection of existing paradigms, but rather, a merger of them. Many educational leaders are synthesizers, trying to combine the best of the ideas currently available. Synthesis involves watching the routes taken by other bicyclists, and then forging a new route that takes into account but is different from their paths.

\section{Assessment of Creativity}

In my original work with divergent reasoning problems having no one best answer, my colleagues and I asked 63 people to create various kinds of products (Lubart and Sternberg, 1995; Sternberg and Lubart, 1991, 1995, 1996) where an infinite variety of responses were possible. Individuals were asked to create products in the realms of writing, art, advertising, and science. In writing, they were asked to write brief stories for which we would give them a choice of titles, such as "Beyond the Edge" or "The Octopus's Sneakers" (cf. description of Rainbow tests mentioned earlier). In art, the participants were asked to produce art compositions with titles such as "The Beginning of Time" or "Earth from an Insect's Point of View." In advertising, they were asked to produce advertisements for products such as a brand of bow tie or a brand of doorknob. In science, they were asked to solve problems such as one asking them how people might detect extraterrestrial 
aliens among us who are seeking to escape detection. Participants created two products in each domain.

Results showed, first, that creativity comprises the components proposed by their investment model of creativity: intelligence, knowledge, thinking styles, personality, and motivation. Second, results showed that creativity is relatively, although not wholly, domain specific. Correlations of ratings of the creative quality of the products across domains were lower than correlations of ratings and generally were at about the 0.4 level. Thus, there was some degree of relationship across domains, at the same time that there was plenty of room for someone to be strong in one or more domains but not in others. Third, measures of creative performance were correlated with conventional tests of abilities. As was the case for the correlations obtained with convergent problems, correlations were higher to the extent that problems on the conventional tests were nonentrenched. For example, correlations were higher with fluid than with crystallized ability tests, and correlations were higher, the more novel the fluid test was. These results confirm that tests of creative intelligence have some overlap with conventional tests (e.g., in requiring verbal skills or the ability to analyze one's own ideas-Sternberg and Lubart, 1995) but also tap skills beyond those measured even by relatively novel kinds of items on the conventional tests of intelligence.

\section{Wisdom}

\section{The Nature of Wisdom}

Wisdom may be the most important attribute to seek in educational leaders. People can be intelligent or creative but not wise. People who use their cognitive skills for evil or even selfish purposes, or who ignore the well-being of others, may be smart—but foolish.

According to my balance theory of wisdom (Sternberg, 1998b, 2001, 2003e), wisdom is defined as the application of intelligence, creativity, and knowledge as mediated by values toward the achievement of a common good through a balance among (a) intrapersonal, (b) interpersonal, and (c) extrapersonal interests, over the (a) short- and (b) long-terms, in order to achieve a balance among (a) adaptation to existing environments, (b) shaping of existing environments, and (c) selection of new environments.

Wisdom is not just about maximizing one's own or someone else's self-interest, but also about balancing various self-interests (intrapersonal) with the interests of others (interpersonal) and about other aspects of the 
context in which one lives (extrapersonal), such as one's city or country or the world. The common good needs also to take into account distributive justice: the rights of individuals and subgroups within any collectivity, and what is as nearly fair as possible to all.

A person could be practically intelligent, but use his or her practical intelligence toward bad or selfish ends. In wisdom, one certainly may seek good ends for oneself, but one also seeks common good outcomes for others. If one's motivations are to maximize certain people's interests and minimize other people's, wisdom is not involved. In wisdom, one seeks a common good, realizing that this common good may be better for some than for others.

Problems requiring wisdom always involve at least some element of each of intrapersonal, interpersonal, and extrapersonal interests. For example, one might decide that it is wise to take advantage of a particular study opportunity abroad, a decision that seemingly involves only one person. But many people are typically affected by an individual's decision to go away to study_-significant others, perhaps children, perhaps parents and friends. And the decision always has to be made in the context of what the whole range of available options is.

What kinds of considerations might be included under each of the three kinds of interests? Intrapersonal interests might include the desire to enhance one's popularity or prestige, to make more money, to learn more, to increase one's spiritual well-being, to increase one's power, and so forth. Interpersonal interests might be quite similar, except as they apply to other people rather than oneself. Extrapersonal interests might include contributing to the welfare of one's school, helping one's community, contributing to the well-being of one's country, or serving God, and so forth. Different people balance these interests in different ways. At one extreme, a malevolent dictator might emphasize his or her own personal power and wealth; at the other extreme, a saint might emphasize only serving others and God.

Wisdom involves a balancing not only of the three kinds of interests but also of three possible courses of action in response to this balancing: adaptation of oneself or others to existing environments; shaping of environments in order to render them more compatible with oneself or others; and selection of new environments.

There are five primary sources of differences directly affecting the balance processes. Consider, as an example, a teacher who has been instructed by a chairperson to spend almost all of his time teaching in a way so as to maximize students' scores on standardized tests, but who believes that the chairperson is essentially forcing him to abandon truly educating his students. 
1. Goals. People may differ in terms of the extent to which they seek a common good, and thus in the extent to which they aim for the essential goal of wisdom. They also may differ in terms of what they view as the common good. The teacher may believe that it is not in the children's best interest to engage in what he views as mindless drills for a test. The chairperson, however, may have a different view. The teacher is thus left with the responsibility of deciding what is in the best interests of all concerned.

2. Balancing of responses to environmental contexts. People may differ in their balance of responses to environmental contexts. Responses always reflect in the interaction of the individual making the judgment and the environment, and people can interact with contexts in myriad ways. The teacher may adapt to the environment and do exactly what the chairperson has told him to do; or shape the environment and do exactly what he believes he should do; or try to find some balance between adaptation and shaping that largely meets the chairperson's goals but also largely meets his own. Or the teacher may decide that the environment of the school is sufficiently aversive to his or her philosophy of teaching that he would prefer to teach at another school.

3. Balancing of interests. People may balance interests in different ways. The teacher must decide how to balance his own interests in good teaching and also in staying on good terms with the chairperson; the children's interests in learning but also doing well on the standardized tests; the parents' interests in having well-educated children; and so on.

4. Balancing of short- and long-terms. People may differ in their emphases. The teacher may believe that, in the long run, a proper education involves much more than preparing for statewide tests, but at the same time realize that, in the short run, the children's scores on the tests will affect their future as well as his future and possibly that of his chairperson and school.

5. Values. People have different values mediating their use of tacit knowledge in the balancing of interests and responses. Values may vary somewhat across space and time, as well as among individuals within a given cultural context. The teacher's values may require him to diverge at least somewhat from the instructions of the chairperson. Another teacher's values might lead him to do what the school principal says, regardless of how he personally feels. 
Some leaders are intelligent and creative, but foolish. They lack wisdom. What are the characteristics of leaders who are smart, but foolish? Consider five characteristics, according to Sternberg (2002).

The first is unrealistic optimism with respect to the long-term consequences of what they do. They may believe themselves to be so smart that they believe that, whatever they do, it will work out all right. They may overly trust their own intuitions, believing that their brilliance means that they can do no wrong.

The second is egocentrism. Many smart leaders have been so highly rewarded in their lives that they lose sight of the interests of others. They start to act as though the whole world revolves around them. In doing so, they often set themselves up for downfalls, as happened to both Presidents Nixon and Clinton, the former in the case of Watergate, the latter in the case of "Monicagate."

The third characteristic is a sense of omniscience. Smart leaders typically know a lot. They get in trouble, however, when they start to think they "know it all." They may have expertise in one area, but then, start to fancy themselves experts in practically everything. At that point, they become susceptible to remarkable downfalls because they act as experts in areas where they are not, and can make disastrous mistakes in doing so.

The fourth characteristic is a sense of omnipotence. Many smart leaders find themselves in positions of substantial power. Sometimes they lose sight of the limitations of their power and start to act as though they are omnipotent. Several U.S. presidents as well as presidents of other countries have had this problem, leading their countries to disasters on the basis of personal whims. Adolf Hitler, Josef Stalin, Mobutu Sese Seko, and Idi Amin come to mind as examples. Many corporate chieftains have also started to think of themselves as omnipotent, unfortunately, cooking the books of their corporations at will.

The fifth characteristic is a sense of invulnerability. Not only do the individuals think they can do anything; they also believe they can get away with it. They believe that either they are too smart to be found out or, even if found out, they will escape any punishment for misdeeds. The result is the kind of disasters the United States has seen in the recent Enron, Worldcom, and Arthur Andersen debacles.

\section{Assessment of Wisdom}

My work on wisdom is relatively recent (Sternberg, 1998b, 2002) and is still "work-in-progress"; my colleagues and I are developing and validating various assessments of wisdom. Because both wisdom and practical intelligence are measured through scenario-based measures, it might be useful 
to review results obtained for practical intelligence (Sternberg et al., 2000). Keep in mind that practical intelligence is related to wisdom but is not the same as wisdom. A person could be practically intelligent and look out only for his or her own interests. A wise person never could look out only for him or herself.

Wisdom scenarios differ from practical-intelligence scenarios in that they more involve balancing of interests toward a common good. Here is an example of a scenario used in our current research:

\begin{abstract}
Felicia and Alexander have been in an intimate relationship for their entire four years of college. Felicia has now been accepted for graduate school in French by a prestigious graduate program in northern California. Alexander was not admitted to the law school in this university, nor to any other law school in the northern California area. Alexander was admitted to a good although not outstanding law school in southern California, but he was also admitted to an outstanding law school in Massachusetts. Felicia has no viable opportunities for graduate study on the East Coast, at least at this time. Alexander is trying to decide whether to attend the less prestigious law school in southern California or the more prestigious one in Massachusetts. He would like to continue the relationship, as would Felicia, and both ultimately hope to get married to each other. A complicating factor is that the law school in Massachusetts has offered Alexander a half-scholarship, whereas the law school in southern California has not offered financial aid for the first year, although it has indicated that there is a possibility of financial aid in subsequent years. Alexander's parents have indicated that while they would be willing to pay his half-tuition for the more prestigious law school, they do not believe it is fair to ask them to pay full tuition for the less prestigious one. They also believe his going to the less prestigious law school will only hurt Alexander's career advancement. Felicia is torn and is leaving it to Alexander to decide what to do. What should Alexander do and why?
\end{abstract}

We do not yet have data on how students respond to these problems. We do have data on people's implicit theories of wisdom, which are consistent with, although they do not provide a direct test of, the balance theory (Sternberg, 1985b). In one study, 200 professors each of art, business, philosophy, and physics were asked to rate the characteristicness of each of the behaviors obtained in a prestudy from the corresponding population with respect to the professors' ideal conception of each of an ideally wise, intelligent, or creative individual in their occupation. Laypersons were also asked to provide these ratings but for a hypothetical ideal individual without regard to occupation. Correlations were computed across the three ratings. In each group except philosophy, the highest correlation was between wisdom and intelligence; in philosophy, the highest correlation was between intelligence and creativity. The correlations between wisdom and intelligence ratings ranged from 0.42 to 0.78 with a median of 0.68 . For all groups, the lowest correlation was between wisdom and creativity (which ranged from -0.24 to 0.48 with a median of 0.27). 
In a second study from Sternberg (1985b), 40 college students were asked to sort three sets of 40 behaviors each into as many or as few piles as they wished. The 40 behaviors in each set were the top-rated wisdom, intelligence, and creativity behaviors from the previous study (Sternberg, 1985b). The sortings then each were subjected to nonmetric multidimensional scaling. For wisdom, six components emerged: reasoning ability, sagacity, learning from ideas and environment, judgment, expeditious use of information, and perspicacity. These components can be compared with those that emerged from a similar scaling of people's implicit theories of intelligence, which were practical problem-solving ability, verbal ability, intellectual balance and integration, goal orientation and attainment, contextual intelligence, and fluid thought. In both cases, cognitive abilities and their use are important. In wisdom, however, some kind of balance of interests appears to emerge as important that does not emerge as important in intelligence, in general.

In a third study (Sternberg, 1985b), 50 adults were asked to rate descriptions of hypothetical individuals for wisdom, intelligence, and creativity. Correlations were computed between pairs of ratings of the hypothetical individuals' levels of the three traits. Correlations between the ratings were 0.94 for wisdom and intelligence, 0.62 for wisdom and creativity, and 0.69 for intelligence and creativity, again suggesting that wisdom and intelligence are highly correlated in people's implicit theories.

The most ambitious program of research on wisdom has been that of Paul Baltes. Over time, Baltes and his colleagues (e.g., Baltes et al., 1992; Baltes and Staudinger, 1993) have collected a wide range of data showing that wisdom can be studied from an explicit-theoretical base. For example, Staudinger et al. (1997) found that measures of intelligence (as well as personality) overlap with but are non-identical to measures of wisdom in terms of constructs measured. And, Staudinger et al. (1992) showed that human-services professionals outperformed a control group on wisdomrelated tasks. They also showed that older adults performed as well on such tasks as did younger adults, and that older adults did better on such tasks if there was a match between their age and the age of the fictitious characters about whom they made judgments. Baltes et al. (1995) found that older individuals nominated for their wisdom performed as well as did clinical psychologists on wisdom-related tasks. They also showed that up to the age of 80 , older adults performed as well on wisdom tasks as did younger adults. In a further set of studies, Staudinger and Baltes (1996) found that performance settings that were relevant to the lives of their participants and that provided for actual or "virtual" interaction of minds through collaborative discourse and endeavors increased wisdom-related performance substantially. 


\section{Synthesis}

What conclusions can be drawn from the WICS framework?

\section{The Basic Relationships}

The WICS theory views intelligence, creativity, and wisdom as different, but as involving fundamental similarities. The basis for "intelligence" narrowly defined, as it is measured by successful intelligence, is the analytical aspect of successful intelligence. The basis for creativity is the creative aspect of successful intelligence. And the basis for wisdom is the practical aspect of successful intelligence, and, in particular, tacit knowledge. Thus, successful intelligence lies at the basis of conventional intelligence, creativity, and wisdom.

Successful intelligence is a basis for conventional intelligence, creativity, and wisdom, but there is more to each these constructs than just successful intelligence. Several components are also involved.

\section{The Role of Components}

Metacomponents Metacomponents play a key role in intelligence, creativity, and wisdom. They form the central executive functions without which none of these three attributes could operate. To think intelligently, creatively, or wisely, one needs to be able to recognize the existence of problems, define the problems, formulate strategies to solve the problems, and so forth. The difference is in the kinds of problems to which they are applied.

In intelligence, they are applied to several kinds of problems. First, when they are applied to relatively familiar kinds of problems that are somewhat abstracted from the world of everyday experience, they are applied to problems requiring analytical intelligence. Second, when they are applied to relatively novel kinds of problems that are relatively nonentrenched in nature, they are applied to problems requiring creative intelligence. Third, when they are applied to relatively practical problems that are highly contextualized in nature, they are applied to problems requiring practical intelligence.

All problems requiring creativity require creative intelligence, but not all problems requiring creative intelligence require creativity. The reason is that creativity—at least according to the investment theory-requires more than just creative intelligence. It also requires knowledge, certain thinking styles, certain personality attributes, and certain motivational attributes. Thus, people can be creatively intelligent but not creative. They 
may think in novel ways but perhaps lack the persistence, or the propensity toward risk-taking, or the willingness to grow that one needs in order to be fully creative. Problems requiring full creativity thus tend to be more complex than problems requiring just creative intelligence. For example, a conceptual-projection problem (about grue and bleen), as described earlier, requires creative intelligence. But it does not require creativity in the same sense that writing an important novel does. The novel involves far more of components of creativity than does the conceptual-projection problem. Thus, coping with novelty is only one aspect of creativity.

Metacomponents are especially important for defining and redefining creative problems. As Getzels and Csikszentmihalyi (1976) pointed out, finding and then clearly defining good problems is an essential element of creativity. Metacomponents are also important for monitoring and evaluating one's products. No one, no matter how creative, hits the creative heights every time. A creative individual needs to devise a system to separate his or her own wheat from the chaff.

Metacomponents also apply in the solution of problems requiring wisdom. Indeed, much of the difficulty of a wisdom-related problem is in figuring out exactly what the problem is, whose interests are involved, and what their interests are. One then needs to formulate a strategy to deal with he problem and a way of monitoring whether the strategy is working.

Performance Components. Performance components also are involved in solving each of the three kinds of problems. For example, one almost inevitably needs to make inferences in solving each kind of problem, whether it is in inferring relations in test-like analogy problems, inferring analogical relations in order to propose a new model of a phenomenon based on a model of a phenomenon (such as Freud's applying the hydraulic model to the psyche), or inferring what a participant in a negotiation really is looking for so that one can offer a wise solution that balances interests.

Knowledge-Acquisition Components. Finally, knowledge-acquisition components are involved in all three kinds of problems as well.

In learning the meanings of new words embedded in context, the reader has to separate helpful and relevant information in context from extraneous material that is irrelevant to or may actually get in the way of learning the words' meanings. Moreover, the reader must combine the selected information into a meaningful whole, using past information about the nature of words as a guide. Deciding what things would be useful for defining a new word and deciding what to do with these useful things once they are isolated are processes that are guided by the use of old information. The reader constantly seeks to connect the context of the unknown word to something with which he or she is familiar. Thus, processing the available 
information requires three distinct operations: (a) locating relevant information in context, (b) combining this information into a meaningful whole, and (c) interrelating this information to what the reader already knows. These processes are referred to from now on as selective encoding, selective combination, and selective comparison, respectively.

\section{Coping with Novelty Skills}

Coping with novelty is relevant in each of conventional intelligence, creativity, and wisdom. In conventional intelligence, coping with novelty is involved in fluid abilities (see Carroll, 1993; Cattell, 1971). It is the essential ingredient of creative thinking. And most wisdom problems are at least somewhat novel; in other words, they present new aspects that old problems have not presented. When problems are more routine, they may be referred to as requiring common sense, but they are not likely to be referred to as requiring wisdom.

\section{Practical Skills}

Practical skills are involved in all three sets of skills as well. They are probably least involved in conventional intelligence. Most would apply to knowing what kinds of strategies and solutions are expected in taking tests and in school (Williams et al., 1996, 2002). They are required in creativity to render ideas so that they can be implemented and so that one can convince others of the worth of these ideas. And they are required in wisdom to solve the problems. Indeed, tacit knowledge is a basis for wise thinking.

\section{WICS and Leadership}

WICS integrates many of the aspects of previous theories of leadership. It involves aspects of trait theory because it specifies the characteristics of a person needed for successful leadership. It involves aspects of behavioral theory because it also suggests the behaviors that must emanate from these characteristics, such as acting in ways that take into account the interests of all stakeholders. It involves aspects of situational theories because the situation is so important in the contextual aspect of the theory of practical intelligence: What is practical depends on the context in which it is done. And it involves aspects of transformational leadership in that the paradigmrejecting forms of creative leadership involve transforming an organization.

Educational leadership involves three basic elements. Creativity is used to generate ideas for leadership. Academic, or analytical intelligence is used to analyze the value of these ideas; practical intelligence is used to 
implement the ideas and to persuade other people of their value. Wisdom is used to ensure the ideas represent a common good for all. The critical aspect of the theory is that all of creativity, intelligence, and wisdom are largely decisions: One has to decide to approach a problem creatively, analytically, practically, and wisely.

In terms of selection of leaders, WICS implies that one should pay some but not too much attention to the educational credentials that usually form a major part of an individual's record. Schools traditionally have emphasized memory and analytical skills substantially more than they have emphasized creative and practical skills. WICS implies that more attention should be paid to creative and practical intelligence and, more generally, to creativity as a whole and to wisdom.

In terms of development of leaders, WICS implies that leadership skills and attitude can be developed in anyone-that leadership is in large part a decision that anyone can make. Developing leaders involves developing their decision-making skills so that they decide in ways that are creative, intelligent, and wise. For example, they would be encouraged to take risks (creative thinking), to ask whether the solution to a problem they pose is the best one they can formulate (intelligent thinking), and whether their solution represents a common good (wise thinking).

In terms of assessment of leaders, the WICS model suggests that leaders be evaluated for the creativity, intelligence, and wisdom of their decision making and their interactions with followers and superiors. Often, supervisors do not know exactly what qualities to look for in evaluating leadership in subordinates. WICS specifies such qualities in some detail.

In this article, I have discussed evidence that leaders of various kinds are intelligent, creative, and wise. Do leaders need all three aspects? I have argued here that each of the three lines of research described in this article-on intelligence, creativity, and wisdom-represents part of a puzzle. The effective educational leader uses creativity to generate novel ideas, intelligence to ensure they are of high quality, and wisdom to ensure they will be for the common good of all followers.

Consider some examples of applications of WICS. These examples are at three levels of leadership: teacher, principal, and superintendent.

Consider a first example. A teacher has to decide whether to organize a dramatic production for her fourth-grade classroom. She believes in the value of dramatic productions, and the one she has in mind is of a wellknown children's play. But she is under a lot of pressure from the principal and the school district to concentrate on basic skills, and she is concerned that producing a play may not be viewed in a favorable light. So she would like to do a dramatic production and at the same time be able to convince the administration that the play is a worthwhile activity for the children in 
terms of addressing the issue of basic skills. She has to be creative in figuring out a way to do this, such as by having children read and analyze the play first. She has to be analytic in deciding whether her plans indeed address students' basic skills. She has to be practical in convincing administrators of the value of her plan. And she has to be wise in all this by doing what is best for the children, their parents, and for the school.

Consider as a second example a decision of a school principal regarding how to deal with low reading scores among the students in her school. Creativity would be involved in planning an intervention that would raise reading levels and hence scores among the pupils. Analytical intelligence is involved in determining whether the proposed plan is indeed one that can be shown to make analytical sense in terms of what is known about reading. Practical intelligence is involved in deciding whether the plan is workable in the school, and to persuade various stakeholders to buy into the plan. Wisdom is involved in making sure the plan represented a common good for all - that it helps students, but also helps the reputation of the school, is fair to teachers in terms of what it requires of them in extra time and effort, does not put an undue burden on parents, and so on.

As a third example, consider a decision of a school superintendent as to whether to renew a contract with a commercial food-service company that provides food to the district. The price for the district is extremely competitive, but that is in part because the menus have a disproportionate amount of food that students like but that could be described as "fast food." It is relatively high in sugar and fat content and low in nutritional value. The superintendent is creative in deciding whether the terms can be renegotiated to provide more nutritive but nevertheless palatable food at a competitive price, or whether another vendor can be found who will do this. He is analytically intelligent in determining whether any new proposed plan meets budgetary, nutritional, and palatability requirements. He is practically intelligent in negotiating the best deal. And he is wise in ensuring that the deal is the best for all stakeholders in the school district. For example, he may come to believe that no matter how cost-efficient the current contract is, it cannot be justified because of the poor nutritional value for the students.

\section{SUMMARY}

In sum, the components of intelligence are at the base of successful intelligence, creativity, and wisdom. They are applied in intelligence, broadly defined, to experience in order to adapt to, shape, and select environments. When the components are involved in fairly abstract but familiar kinds of tasks, they are used analytically. When they are involved in relatively 
novel tasks and situations, they are used creatively. When they are involved in adaptation to, shaping of, and selection of environments, they are used practically.

Creative intelligence is a part of but not the entirety of human creativity. Creativity also involves aspects of knowledge, styles of thinking, personality, and motivation, as well as these psychological components in interaction with the environment. An individual with the intellectual skills for creativity but without the other personal attributes is unlikely to do creative work.

Wisdom results from the application of successful intelligence and creativity toward the common good through a balancing of intrapersonal, interpersonal, and extrapersonal interests over the short- and long terms. Wisdom is not just a way of thinking about things; it is a way of doing things. If people wish to be wise, they must act wisely, not just think wisely. We all can.

\section{CONCLUSIONS}

This article has presented a theory of educational leadership-WICS. The theory may have some appeal because it attempts to view educational leadership broadly. Leaders who are smart but not creative or wise, who are creative but not wise, are less likely to be the leaders who have enduring impact. Of course, some psychologists believe the theory departs too much from the conventional theory of general intelligence (Spearman, 1904): Some disagree with parts of the theory (e.g., Brody, 2003a,b) and some disagree with the whole thing, vehemently (Gottfredson, 2003a,b). Others believe the theory does not depart from conventional $g$ theory enough (Gardner, 1983). Still others have theories that are more compatible, in spirit, with that proposed here, at least for intelligence (Ceci, 1996). The theory is rather newer than that of, say, Spearman (1904) and has much less work to support it, as well as a lesser range of empirical support. I doubt the theory is wholly correct—scientific theories so far have not been-but I hope at the same time it serves as a broader basis for future theories than, say, Spearman's theory of general intelligence. No doubt, there will be those who wish to preserve this and related older theories, and those who continue to do research that replicates many times that so-called general intelligence does indeed matter for success in many aspects of life. I agree. At the same time, I suspect endless replication is not sufficient, and that those who keep replicating the findings of the past are unlikely to serve as the positive educational leaders of the future. But only time will tell. As noted earlier, there is typically some value to replication in science, although after 
the point where a point is established, it seems more to continue to produce papers than to produce new scientific breakthroughs.

In selecting the educational leaders of tomorrow, three important factors to consider are intelligence, creativity, and wisdom-synthesized so that they work together effectively. These are not the only attributes that matter. For example, motivation and energy are important as well. However, motivation is partly (although not exclusively) situational. With the proper environment, anyone can be motivated to achieve.

This essay has concentrated on "tests" as measures of intelligence and creativity, but they represent only one of many ways of assessing these attributes. Interviews, questionnaires, letters of recommendation, and project work all can help in assessing these attributes.

The educational system in the United States, as in many other countries, places great emphasis on instruction and assessments that tap two important skills: memory and analysis. Students who are adept at these two skills tend to profit from the educational system because the ability tests, instruction, and achievement tests used all largely measure products and processes emanating from these two kinds of skills. There is a problem, however-namely, that children whose strengths are in other kinds of skills may be shortchanged by this system. These children might learn and test well, if only they were given an opportunity to play to their strengths, such as of analytical, creative, or practical abilities rather than their weaknesses in these and related skills.

As a society, we can create a closed system that advantages only certain types of children and that disadvantages other types. Children who excel in memory and analytical abilities may end up doing well on ability tests and achievement tests, and hence find the doors of opportunity open to them. Children who excel in other abilities may end up doing poorly on the tests, and find the doors shut. By treating children with alternative patterns of abilities as losers, society may end up creating harmful self-fulfilling prophecies.

Institutions should consider pooling their resources and developing a common model and common methods of assessment. By working separately, they fail to leverage their strengths and to share information regarding the best ways to make decisions. In essence, each institution "reinvents the wheel." A consortium would be far more powerful than each institution working on its own. WICS is one model such a consortium might use. Doubtless there are many others. The important thing is to work together toward a common good-toward devising the best ways to select students so as to maximize their positive future impact. We all wish our educational leaders to show wisdom. We ourselves need to do the same. 


\section{ACKNOWLEDGMENTS}

Preparation of this report was supported by the U.S. Institute of Educational Sciences (IES) of the U.S. Department of Education, the National Science Foundation, the Army Research Institute, the W. T. Grant Foundation, and the Rockefeller Foundation. The IES Grant was Award \#31-1992701 as administered by the Temple University Laboratory for Student Success. Grantees undertaking such projects are encouraged to express their own views, which do not necessarily represent the funding agencies.

\section{REFERENCES}

Adelson, B. (1984). When novices surpass experts: The difficulty of a task may increase with expertise. J. Exp. Psychol.: Learn. Memory Cogn. 10(3): 483-495.

Amabile, T. M. (1983). The Social Psychology of Creativity, Springer, New York.

Amabile, T. M. (1996). Creativity in Context, Westview, Boulder, CO.

Antonakis, J., Cianciolo, A. T., and Sternberg, R. J. (2004a). Leadership: Past, present, and future. In Antonakis, J., Cianciolo, A. T., and Sternberg, R. J. (eds.), The Nature of Leadership, Sage, Thousand Oaks, CA, pp. 3-15.

Antonakis, J., Cianciolo, A. T., and Sternberg, R. J. (eds.). (2004b). The Nature of Leadership, Sage, Thousand Oaks, CA.

Ayman, R. (2004). Situational and contingency approaches to leadership. In Antonakis, J., Cianciolo, A. T., and Sternberg, R. J. (eds.), The Nature of Leadership, Sage, Thousand Oaks, CA, pp. 148-170.

Baehr, M. E. (1992). Predicting Success in Higher Level Positions: A Guide to the System for Testing and Evaluation of Potential, Quorum, New York.

Bales, R. F. (1951). Interaction process analysis: A method for the study of small groups. Addison-Wesley, Reading, MA.

Baltes, P. B., Smith, J., and Staudinger, U. M. (1992). Wisdom and successful aging. In Sonderegger, T. B. (ed.), Psychology and Aging, University of Nebraska Press, Lincoln, NE, pp. 123-167.

Baltes, P. B., and Staudinger, U. M. (1993). The search for a psychology of wisdom. Curr. Direct. Psychol. Sci. 2: 75-80.

Baltes, P. B., and Staudinger, U. M. (2000). Wisdom: A metaheuristic (pragmatic) to orchestrate mind and virtue toward excellence. Am. Psychol. 55: 122-135.

Baltes, P. B., Staudinger, U. M., Maercker, A., and Smith, J. (1995). People nominated as wise: A comparative study of wisdom-related knowledge. Psychol. Aging 10: 155-166.

Bandura, A. (1997). Self-efficacy: The Exercise of Control, Freeman, New York.

Barnes, M. L., and Sternberg, R. J. (1989). Social intelligence and decoding of nonverbal cues. Intelligence 13: 263-287.

Barron, F., and Harrington, D. M. (1981). Creativity, intelligence, and personality. Annu. Rev. Psychol. 32: 439-476.

Bass, B. M. (1985). Leadership and Performance Beyond Expectations, Free Press, New York.

Bass, B. M. (1998). Transformational Leadership: Industrial, Military, and Educational Impact, Lawrence Erlbaum Associates, Mahwah, NJ.

Bass, B. M. (2002). Cognitive, social, and emotional intelligence of transformational leaders. In Riggio, R. E., Murphy, S. E., and Pirozzolo, F. J. (eds.), Multiple Intelligences and Leadership, Lawrence Erlbaum Associates, Mahwah, NJ, pp. 105-118.

Bass, B. M., and Avolio, B. J. (eds.). (1994). Improving Organizational Effectiveness Through Transformational Leadership, Sage, Thousand Oaks, CA.

Bass, B. M., and Avolio, B. J. (1995). MLQ Multifoactor Leadership Questionnaire for Research: Premission Set, Mindgarden, Redwood City, CA. 
Bass, B. M., Avolio, B. J., and Atwater, L. (1996). The transformational and transactional leadership of men and women. Int. Rev. Appl. Psychol. 45: 5-34.

Bateson, G. (1979). Mind and Nature, Wildwood House, London.

Bird, C. (1940). Social Psychology, Appleton-Century, New York.

Blake, R. R., and Mouton, J. S. (1964). The Managerial Grid, Gulf Publishing Group, Houston.

Boring, E. G. (1923, June 6). Intelligence as the tests test it. New Republic, 35-37.

Bowers, K. S., Regehr, G., Balthazard, C., and Parker, K. (1990). Intuition in the context of discovery. Cogn. Psychol. 22: 72-109.

Bransford, J. D., and Stein, B. (1984). The IDEAL Problem Solver, Freeman, New York.

Brody, N. (2003a). Construct validation of the Sternberg Triarchic abilities test: Comment and reanalysis. Intelligence 31(4): 319-329.

Brody, N. (2003b). What Sternberg should have concluded. Intelligence 31(4): 339342.

Brown, A. L., and Ferrara, R. A. (1985). Diagnosing zones of proximal development. In Wertsch, J. V. (ed.). Culture, Communication, and Cognition: Vygotskian Perspectives, Cambridge University Press, New York, NY, pp. 273-305.

Budoff, M. (1968). Learning potential as a supplementary assessment procedure. In Hellmuth, J. (ed.), Learning Disorders, Vol. 3, Special Child, Seattle, WA, pp. 295-343.

Burns, J. M. (1978). Leadership, Harper \& Row, New York.

Campbell, D. T. (1960). Blind variation and selective retention in creative thought and other knowledge processes. Psychol. Rev. 67: 380-400.

Carroll, J. B. (1993). Human Cognitive Abilities: A Survey of Factor-Analytic Studies, Cambridge University Press, New York.

Caruso, D. R., Mayer, J. D., and Salovey, P. (2002). Emotional intelligence and emotional leadership. In Riggio, R. E., Murphy, S. E., and Pirozzolo, F. J. (eds.), Multiple Intelligences and Leadership, Lawrence Erlbaum Associates, Mahwah, NJ, pp. 5574.

Cattell, R. B. (1971). Abilities: Their Structure, Growth and Action, Houghton Mifflin, Boston.

Cattell, R. B., and Cattell, H. E. P. (1973). Measuring Intelligence with the Culture Fair Tests, Institute for Personality and Ability Testing, Champaign, IL.

Ceci, S. J. (1996). On Intelligence, revised and expanded edition, Harvard University Press, Cambridge, MA.

Clement, J. (1989). Learning via model construction and criticism: Protocol evidence on sources of creativity in science. In Glover, G., Ronning, R., and Reynolds, C. (eds.), Handbook of Creativity, Plenum, New York, pp. 341-381.

Crutchfield, R. (1962). Conformity and creative thinking. In Gruber, H., Terrell, G., and Wertheimer, M. (eds.), Contemporary Approaches to Creative Thinking, Atherton Press, New York, pp. 120-140.

Cziko, G. A. (1998). From Blind to creative: In defense of Donald Campbell's selectionist theory of human creativity. J. Creat. Behav. 32: 192-208.

Davidson, J. E., and Sternberg, R. J. (1984). The role of insight in intellectual giftedness. Gifted Child Quart. 28: 58-64.

Day, J. D., Engelhardt, J. L., Maxwell, S. E., and Bolig, E. E. (1997). Comparison of static and dynamic assessment procedures and their relation to independent performance. J. Educ. Psychol. 89(2): 358-368.

Dellas, M., and Gaier, E. L. (1970). Identification of creativity: The individual. Psychol. Bull. 73: $55-73$.

Dewey, J. (1933). How We Think, Heath, Boston.

Ericsson, K. A. (ed.) (1996). The Road to Excellence, Lawrence Erlbaum Associates, Mahwah, NJ.

Feuerstein, R. (1979). The Dynamic Assessment of Retarded Performers: The Learning Potential Assessment Device Theory, Instruments, and Techniques, University Park Press, Baltimore, MD.

Fiedler, F. E. (1978). The contingency model and the dynamics of the leadership process. In Bekowitz, L. (ed.), Advances in Experimental Social Psychology, Vol. 11, Academic Press, New York, pp. 59-112. 
Fiedler, F. E. (2002). The curious role of cognitive resources in leadership. In Riggio, R. E., Murphy, S. E., and Pirozzolo, F. J. (eds.), Multiple Intelligences and Leadership, Lawrence Erlbaum Associates, Mahwah, NJ, pp. 91-104.

Fiedler, F. E., and Link, T. G. (1994). Leader intelligence, interpersonal stress, and task performance. In Sternberg, R. J., and Wagner, R. K. (eds.), Mind in Context: Interactionist Perspectives on Human Intelligence, Cambridge University Press, New York, pp. 152-167.

Findlay, C. S., and Lumsden, C. J. (1988). The creative mind: Toward an evolutionary theory of discovery and invention. J. Soc. Biol. Struc. 11: 3-55.

Finke, R. (1990). Creative Imagery: Discoveries and Inventions in Visualization, Erlbaum, Hillsdale, NJ.

Finke, R. (1995). A creative insight and preinventive forms. In Sternberg, R. J. and Davidson, J. E. (eds.), The Nature of Insight, MIT Press, Cambridge, MA, pp. 255-280.

Frensch, P. A., and Sternberg, R. J. (1989). Expertise and intelligent thinking: When is it worse to know better? In Sternberg, R. J. (ed.), Advances in the Psychology of Human Intelligence, Vol. 5, Lawrence Erlbaum Associates, Hillsdale, NJ, pp. 157-188.

Garcia, J., and Koelling, R. A. (1966). The relation of cue to consequence in avoidance learning. Psychon. Sci. 4: 123-124.

Gardner, H. (1983). Frames of Mind: The Theory of Multiple Intelligences, Basic Books, New York.

Gardner, H. (1991). The Unschooled Mind, Basic Books, New York.

Gardner, H. (1993a). Creating Minds, Basic Books, New York.

Gardner, H. (1993b). Multiple Intelligences: The Theory in Practice, Basic Books, New York.

Gardner, H. (1994). The creator's patterns. In Feldman, D. H., Csikszentmihalyi, M., and Gardner, H. (eds.), Changing the World: A Framework for the Study of Creativity, Praeger, Westport, CT, pp. 69-84.

Gardner, H. (1995). Leading Minds, Basic Books, New York.

Gardner, H. (1999). Intelligence Reframed: Multiple Intelligences for the 21st Century, Basic Books, New York.

Gardner, H. (2004). Changing Minds: The Art and Science of Changing Our Own and Other People's Minds, Harvard Business School Press, Boston, MA.

Gardner, H., Krechevsky, M., Sternberg, R. J., and Okagaki, L. (1994). Intelligence in context: Enhancing students' practical intelligence for school. In McGilly, K. (ed.), Classroom Lessons: Integrating Cognitive Theory and Classroom Practice, MIT Press, Cambridge, MA, pp. 105-127.

Getzels, J. W., and Csikszentmihalyi, M. (1976). The Creative Vision: Problem Finding in Art, Van Nostrand, Chicago.

Glover, J. A. (1977). Risky shift and creativity. Soc. Behav. Person. 5(2): 317-320.

Goethals, G. R., Sorenson, G. J., and Burns, J. M. (eds.). (2004), Encyclopedia of Leadership, Sage, Thousand Oaks, CA.

Golann, S. E. (1962). The creativity motive. J. Person. 30: 588-600.

Goleman, D., Boyatzis, R., and McKee, A. (2002). Primal Leadership: Realizing the Power of Emotional Intelligence, Harvard Business School Press, Boston, MA.

Gottfredson, L. S. (2003a). Discussion: On Sternberg's 'Reply to Gottfredson'. Intelligence 31(4): 415-424.

Gottfredson, L. S. (2003b). Dissecting practical intelligence theory: Its claims and evidence. Intelligence 31(4): 343-397.

Gough, H. G., and Woodworth, D. G. (1960). Stylistic variations among professional research scientists. J. Psychol. 49: 87-98.

Grigorenko, E. L., Jarvin, L., and Sternberg, R. J. (2002). School-based tests of the triarchic theory of intelligence: Three settings, three samples, three syllabi. Contemporary Educ. Psychol. 27: 167-208.

Grigorenko, E. L., and Sternberg, R. J. (1998). Dynamic testing. Psychol. Bull. 124: 75-111.

Grigorenko, E. L., and Sternberg, R. J. (2001). Analytical, creative, and practical intelligence as predictors of self-reported adaptive functioning: A case study in Russia. Intelligence 29: $57-73$. 
Gruber, H. E. (1981). Darwin on Man: A Psychological Study of Scientific Creativity, 2nd edn. (original work published 1974), University of Chicago Press, Chicago.

Guilford, J. P. (1968). Intelligence has three facets. Science 160(3828): 615-620.

Guthke, J. (1993). Current trends in theories and assessment of intelligence. In Hamers, J. H. M., Sijtsma, K., and Ruijssenaars, A. J. J. M. (eds.), Learning Potential Assessment, Swets \& Zeitlinger, Amsterdam, pp. 13-20.

Guyote, M. J., and Sternberg, R. J. (1981). A transitive-chain theory of syllogistic reasoning. Cogn. Psychol. 13: 461-525.

Haywood, H. C., and Tzuriel, D. (1992). Epilogue: The status and future of interactive assessment. In Haywood, H. C., and Tzuriel, D. (eds.), Interactive Assessment, Springer-Verlag, New York, pp. 38-63.

Hedlund, J., Forsythe, G. B., Horvath, J. A., Williams, W. M., Snook, S., and Sternberg, R. J. (2003). Identifying and assessing tacit knowledge: Understanding the practical intelligence of military leaders. Leadership Quart. 14: 117-140.

Hersey, P., and Blanchard, K. H. (1969). Management of Organizational Behavior, PrenticeHall, Englewood Cliffs, NJ.

House, R. J. (1971). A path-goal theory of leader effectiveness. Admin. Sci. Quart. 16: 321339.

House, R. J. (1996). Path-goal theory of leadership: Lessons, legacy, and a reformed theory. Leadership Quart. 7: 323-352.

Howe, M. J., Davidson, J. W., and Sloboda, J. A. (1998). Innate talents: Reality or myth? Behav. Brain Sci. 21: 399-442.

Howells, L. T., and Becker, S. W. (1962). Seating arrangement and leadership emergence. J. Abnormal Social Psychol. 64: 148-150.

Hunt, J. G. (2004). What is leadership? In Antonakis, J., Cianciolo, A. T., and Sternberg, R. J. (eds.), The Nature of Leadership, Sage, Thousand Oaks, CA, pp. 19-47.

"Intelligence and its measurement": A symposium (1921). J. Educ. Psychol. 12: 123-147, 195216, 271-275.

Jensen, A. R. (1998). The g Factor: The Science of Mental Ability, Praeger/Greenwood, Westport, CT.

Johnson-Laird, P. N. (1988). Freedom and constraint in creativity. In Sternberg, R. J. (Ed.), The Nature of Creativity, Cambridge University Press, New York, pp. 202-219.

Kaplan, C. A., and Simon, H. A. (1990). In search of insight. Cogn. Psychol. 22: 374-419.

Koestler, A. (1964). The Act of Creation, Dell, New York.

Kuhn, T. S. (1970). The Structure of Scientific Revolutions, 2nd edn., University of Chicago Press, Chicago.

Langley, P., Simon, H. A., Bradshaw, G. L., and Zytkow, J. M. (1987). Scientific Discovery: Computational Explorations of the Creative Processes, MIT Press, Cambridge, MA.

Leavitt, H. J. (1951). Some effects of certain communication patterns on group performance. J. Abnormal Soc. Psychol. 46: 38-50.

Lewin, K., and Lippitt, R. (1938). An experimental approach to the study of autocracy and democracy: A preliminary note. Sociometry 1: 292-300.

Lewin, K., Lippitt, R., and White, R. K. (1939). Patterns of aggressive behavior in experimentally created social climates. J. Soc. Psychol. 10: 271-301.

Lidz, C. S. (Ed.) (1987). Dynamic assessment, The Guilford Press, New York.

Lidz, C. S. (1991). Practitioner's Guide to Dynamic Assessment, Guilford Press, New York.

Lubart, T. I., and Sternberg, R. J. (1995). An investment approach to creativity: Theory and data. In Smith, S. M., Ward, T. B., and Finke, R. A. (eds.), The Creative Cognition Approach, MIT Press, Cambridge, MA.

MacKinnon, D. W. (1962). The nature and nurture of creative talent. Am. Psychol. 17: 484495.

MacKinnon, D. W. (1965). Personality and the realization of creative potential. Am. Psychol. 20: $273-281$.

Mann, R. D. (1959). A review of the relationship between personality and performance in small groups. Psychol. Bull. 56: 241-270. 
Martindale, C. (1999). Biological bases of creativity. In Sternberg R. J. (ed.), Handbook of Creativity, Cambridge University Press, New York, pp. 137-152.

Maslow, A. (1967). The creative attitude. In Mooney, R. L. and Rasik, T. A. (eds.), Explorations in Creativity, Harper \& Row, New York, pp. 43-57.

McClelland, D. C., Atkinson, J. W., Clark, R. A., and Lowell, E. L. (1953). The Achievement Motive, Appleton-Century-Crofts, Inc., New York.

McGregor, D. M. (1960). The Human Side of Enterprise, McGraw-Hill, New York.

Milgram, S. (1974). Obedience to Authority, Harper \& Row, New York.

Mischel, W., Shoda, Y., and Rodriguez, M. L. (1989). Delay of gratification in children. Science 244: 933-938.

Morrow, I. J., and Stern, M. (1990). Stars, adversaries, producers, and phantoms at work: A new leadership typology. In Clark, K. E., and Clark, M. B. (eds.), Measures of Leadership, Center for Creative Leadership, Greensboro, NC, pp. 419-440.

Mumford, M. D., and Connelly, M. S. (1991). Leaders as creators: Leader performance and problem solving in ill-defined domains. Leadership Quart. 2: 289-316.

Mumford, M. D., Scott, G. M., Gaddis, B., and Strange, J. M. (2002). Leading creative people: Orchestrating expertise and relationships. Leadership Quart. 13: 705-750.

Ochse, R. (1990). Before the Gates of Excellence, Cambridge University Press, New York.

Perkins, D. N. (1981). The Mind's Best Work, Harvard University Press, Cambridge, MA.

Perkins, D. N. (1995). Insight in minds and genes. In Sternberg, R. J., and Davidson, J. E. (eds.), The Nature of Insight, MIT Press, Cambridge, MA, pp. 495-534.

Riggio, R. E., Murphy, S. E., and Pirozzolo, F. J. (2002), Multiple Intelligences and Leadership, Lawrence Erlbaum Associates, Mahwah, NJ.

Roe, A. (1952). The Making of a Scientist, Dodd, Mead, New York.

Rogers, C. R. (1954). Toward a theory of creativity. ETC: Rev. Gen. Semantics 11: 249260.

Rogoff, B. (1990). Apprenticeship in Thinking. Cognitive Development in Social Context, Oxford University Press, New York, NY.

Rubenson, D. L., and Runco, M. A. (1992). The psychoeconomic approach to creativity. New Ideas Psychol. 10: 131-147.

Sashkin, M. (2004). Transformational leadership approaches: A review and synthesis. In Antonakis, J., Cianciolo, A. T., and Sternberg, R. J. (eds.), The Nature of Leadership, Sage, Thousand Oaks, CA, pp. 171-196.

Schmidt, F. L., and Hunter, J. E. (1998). The validity and utility of selection methods in personnel psychology: Practical and theoretical implications of 85 years of research findings. Psychol. Bull. 124: 262-274.

Shartle, C. L. (1951). Studies of naval leadership. Part I. In Guetzkow, H. (ed.), Group, Leadership and Men, Carnegie Press, Pittsburgh, PA, pp. 119-133.

Simonton, D. K. (1994). Greatness: Who Makes History and Why? Guilford, New York.

Simonton, D. K. (1997). Creative productivity: A predictive and explanatory model of career trajectories and landmarks. Psychol. Rev. 104: 66-89.

Simonton, D. K. (1998). Donald Campbell's model of the creative process: Creativity as blind variation and selective retention. J. Creative Behav. 32: 153-158.

Sloman, S. A. (1996). The empirical case for two systems of reasoning. Psychol. Bull. 119: 322.

Sosik, J. J., and Megerian, L. E. (1999). Understanding leader emotional intelligence and performance: The role of self-other agreement on transformational leadership perceptions. Group Org. Manag. 24: 367-390.

Spearman, C. (1904). 'General intelligence,' objectively determined and measured. Am. J. Psychol. 15(2): 201-293.

Spearman, C. (1927). The Abilities of Man, Macmillan, London.

Spreitzer, G. M., McCall, M. W. Jr., and Mahoney, J. D. (1997). Early identification of international executive potential. J. Appl. Psychol. 82: 6-29.

Staudinger, U. M., and Baltes, P. M. (1996). Interactive minds: A facilitative setting for wisdom-related performance? J. Person. Soc. Psychol. 71: 746-762. 
Staudinger, U. M., Lopez, D. F., and Baltes, P. B. (1997). The psychometric location of wisdom-related performance: Intelligence, personality, and more? Person. Soc. Psychol. Bull. 23: 1200-1214.

Staudinger, U. M., Smith, J., and Baltes, P. B. (1992). Wisdom-related knowledge in life review task: Age differences and the role of professional specialization. Psychol. Aging 7: 271281.

Sternberg, R. J. (1977). Intelligence, Information Processing, and Analogical Reasoning: The Componential Analysis of Human Abilities, Lawrence Erlbaum Associates, Hillsdale, NJ.

Sternberg, R. J. (1980a). Representation and process in linear syllogistic reasoning. J. Exp. Psychol. Gen. 109: 119-159.

Sternberg, R. J. (1980b). Sketch of a componential subtheory of human intelligence. Behav. Brain Sci. 3: 573-584.

Sternberg, R. J. (1981). Intelligence and nonentrenchment. J. Educ. Psychol. 73: 1-16.

Sternberg, R. J. (1982). Natural, unnatural, and supernatural concepts. Cogn. Psychol. 14: 451488.

Sternberg, R. J. (1983). Components of human intelligence. Cognition 15: 1-48.

Sternberg, R. J. (1984). Toward a triarchic theory of human intelligence. Behav. Brain Sci. 7: 269-287.

Sternberg, R. J. (1985a). Beyond IQ: A Triarchic Theory of Human Intelligence, Cambridge University Press, New York.

Sternberg, R. J. (1985b). Implicit theories of intelligence, creativity, and wisdom. J. Person. Soc. Psychol. 49(3): 607-627.

Sternberg, R. J. (1987a). Most vocabulary is learned from context. In McKeown, M. G., and Curtis, M. E. (eds.), The Nature of Vocabulary Acquisition, Lawrence Erlbaum Associates, Hillsdale, NJ, pp. 89-105.

Sternberg, R. J. (1987b). The psychology of verbal comprehension. In Glaser, R. (ed.), Advances in Instructional Psychology, Vol. 3, Lawrence Erlbaum Associates, Hillsdale, NJ, pp. $97-151$.

Sternberg, R. J. (ed.). (1988). The Nature of Creativity: Contemporary Psychological Perspectives, Cambridge University Press, New York.

Sternberg, R. J. (1990). Metaphors of Mind, Cambridge University Press, New York.

Sternberg, R. J. (1993). Sternberg Triarchic Abilities Test, Unpublished test.

Sternberg, R. J. (1994). Answering questions and questioning answers. Phi Delta Kappan 76(2): 136-138.

Sternberg, R. J. (1995). In Search of the Human Mind, Harcourt Brace College Publishers, Orlando, FL.

Sternberg, R. J. (1997). Successful Intelligence, Plume, New York.

Sternberg, R. J. (1998a). Abilities are forms of developing expertise. Educ. Res. 27: 11-20.

Sternberg, R. J. (1998b). A balance theory of wisdom. Rev. Gen. Psychol. 2: 347-365.

Sternberg, R. J. (ed.). (1998c). Handbook of Creativity, Cambridge University Press, New York.

Sternberg, R. J. (1998d). Metacognition, abilities, and developing expertise: What makes an expert student? Instruct. Sci. 26: 127-140.

Sternberg, R. J. (1999a). Intelligence as developing expertise. Contemporary Educ. Psychol. 24: $359-375$.

Sternberg, R. J. (1999b). A propulsion model of types of creative contributions. Rev. Gen. Psychol. 3: 83-100.

Sternberg, R. J. (1999c). The theory of successful intelligence. Rev. Gen. Psychol. 3: 292-316.

Sternberg, R. J. (ed.). (2000). Handbook of Intelligence, Cambridge University Press, New York.

Sternberg, R. J. (2001). Why schools should teach for wisdom: The balance theory of wisdom in educational settings. Educ. Psychol. 36(4): 227-245.

Sternberg, R. J. (2002). Smart people are not stupid, but they sure can be foolish: The imbalance theory of foolishness. In Sternberg, R. J. (ed.), Why Smart People Can be so Stupid, Yale University Press, New Haven, pp 232-242. 
Sternberg, R. J. (ed.). (2003a). The Anatomy of Impact: What has Made the Great Works of Psychology Great? American Psychological Association, Washington, DC, pp. 223228.

Sternberg, R. J. (ed.). (2003b). Psychologists Defying the Crowd: Stories of Those Who Battled the Establishment and Won, American Psychological Association, Washington, DC.

Sternberg, R. J. (2003c). What is an expert student? Educ. Res. 32(8): 5-9.

Sternberg, R. J. (2003d). WICS: A model for leadership in organizations. Acad. Manag. Learn. Educ. 2: 386-401.

Sternberg, R. J. (2003e). WICS: A Theory of Wisdom, Intelligence, and Creativity, Synthesized, Cambridge University Press, New York.

Sternberg, R. J. (2003f). WICS as a model of giftedness. High Ability Stud. 14: 109-137.

Sternberg, R. J. (2004a). Culture and intelligence. Am. Psychol. 59: 325-338.

Sternberg, R. J. (2004b). WICS: A model of educational leadership. Educ. Forum 68(2): 108114.

Sternberg, R. J., Castejón, J. L., Prieto, M. D., Hautamäki, J., and Grigorenko, E. L. (2001a). Confirmatory factor analysis of the Sternberg triarchic abilities test in three international samples: An empirical test of the triarchic theory of intelligence. Eur. J. Psychol. Assess. 17(1): $1-16$.

Sternberg, R. J., and Clinkenbeard, P. R. (1995). The triarchic model applied to identifying, teaching, and assessing gifted children. Roeper Rev. 17(4): 255-260.

Sternberg, R. J., and Detterman, D. K. (eds.). (1986). What is Intelligence? Ablex Publishing Corporation Norwood, NJ.

Sternberg, R. J., Ferrari, M., Clinkenbeard, P. R., and Grigorenko, E. L. (1996). Identification, instruction, and assessment of gifted children: A construct validation of a triarchic model. Gifted Child Quart. 40(3): 129-137.

Sternberg, R. J., Forsythe, G. B., Hedlund, J., Horvath, J., Snook, S., Williams, W. M., Wagner, R. K., and Grigorenko, E. L. (2000). Practical Intelligence in Everyday Life, Cambridge University Press, New York.

Sternberg, R. J., and Gardner, M. K. (1982). A componential interpretation of the general factor in human intelligence. In Eysenck, H. J. (ed.), A Model for Intelligence, SpringerVerlag, Berlin, pp. 231-254.

Sternberg, R. J., and Gardner, M. K. (1983). Unities in inductive reasoning. J. Exp. Psychol. Gen. 112: 80-116.

Sternberg, R. J., and Gastel, J. (1989a). Coping with novelty in human intelligence: An empirical investigation. Intelligence 13: 187-197.

Sternberg, R. J., and Gastel, J. (1989b). If dancers ate their shoes: Inductive reasoning with factual and counterfactual premises. Memory Cogn. 17: 1-10.

Sternberg, R. J., and Grigorenko, E. L. (1997, Fall). The cognitive costs of physical and mental ill health: Applying the psychology of the developed world to the problems of the developing world. Eye Psi Chi 2(1): 20-27.

Sternberg, R. J., and Grigorenko, E. L. (2000). Teaching for Successful Intelligence, Skylight Training and Publishing Inc, Arlington Heights, IL.

Sternberg, R. J., and Grigorenko, E. L. (2002a). Dynamic Testing, Cambridge University Press, New York.

Sternberg, R. J., and Grigorenko, E. L. (eds.). (2002b). The General Factor of Intelligence: How General Is It?, Lawrence Erlbaum Associates Mahwah, NJ.

Sternberg, R. J., Grigorenko, E. L., Ferrari, M., and Clinkenbeard, P. (1999). A triarchic analysis of an aptitude-treatment interaction. Eur. J. Psychol. Assess. 15(1): 1-11.

Sternberg, R. J., Grigorenko, E. L., Ngrosho, D., Tantufuye, E., Mbise, A., Nokes, C., Jukes, M., and Bundy, D. A. (2002a). Assessing intellectual potential in rural Tanzanian school children. Intelligence 30: 141-162.

Sternberg, R. J., and Hedlund, J. (2002). Practical intelligence, g, and work psychology. Human Perform. 15(1/2): 143-160.

Sternberg, R. J., and Kalmar, D. A. (1997). When will the milk spoil? Everyday induction in human intelligence. Intelligence 25(3): 185-203. 
Sternberg, R. J., Kaufman, J. C., and Pretz, J. E. (2002b). The Creativity Conundrum: A Propulsion Model of Kinds of Creative Contributions, Psychology Press, New York.

Sternberg, R. J., Kaufman, J. C., and Pretz, J. E. (2003). A propulsion model of creative leadership. Leadership Quart. 14: 455-473.

Sternberg, R. J., and Lubart, T. I. (1991). An investment theory of creativity and its development. Human Dev. 34(1): 1-31.

Sternberg, R. J., and Lubart, T. I. (1995). Defying the Crowd: Cultivating Creativity in a Culture of Conformity, Free Press, New York.

Sternberg, R. J., and Lubart, T. I. (1996). Investing in creativity. Am. Psychol. 51(7): 677-688.

Sternberg, R. J., and Nigro, G. (1980). Developmental patterns in the solution of verbal analogies. Child Dev. 51: 27-38.

Sternberg, R. J., Nokes, K., Geissler, P. W., Prince, R., Okatcha, F., Bundy, D. A., and Grigorenko, E. L. (2001b). The relationship between academic and practical intelligence: A case study in Kenya. Intelligence 29: 401-418.

Sternberg, R. J., and O'Hara, L. (1999). Creativity and intelligence. In Sternberg, R. J. (ed.), Handbook of Creativity, Cambridge University Press, New York, pp. 251-272.

Sternberg, R. J., Okagaki, L., and Jackson, A. (1990). Practical intelligence for success in school. Educ. Leadership 48: 35-39.

Sternberg, R. J., and Powell, J. S. (1983). Comprehending verbal comprehension. Am. Psychol. 38: 878-893.

Sternberg, R. J., Powell, J. S., and Kaye, D. B. (1983). Teaching vocabulary-building skills: A contextual approach. In Wilkinson, A. C. (ed.), Classroom Computers and Cognitive Science, Academic Press, New York, pp. 121-143.

Sternberg, R. J., and the Rainbow Project Collaborators (2005). Augmenting the SAT through assessments of analytical, practical, and creative skills. In Camara, W., and Kimmel, E. (eds.), New Tools for Admission to Higher Education, Lawrence Erlbaum Associates, Mahwah, NJ.

Sternberg, R. J., and the Rainbow Project Team. (2002, February 16). The Rainbow Project: Augmenting the Validity of the SAT, Paper presented to American Academy of Arts and Sciences, Boston, MA.

Sternberg, R. J., the Rainbow Project Collaborators, and University of Michigan Business School Project Collaborators (2004). Theory based university admissions testing for a new millennium. Educ. Psychol. 39(3): 185-198.

Sternberg, R. J., and Rifkin, B. (1979). The development of analogical reasoning processes. $J$. Exp. Child Psychol. 27: 195-232.

Sternberg, R. J., and Smith, C. (1985). Social intelligence and decoding skills in nonverbal communication. Soc. Cogn. 2: 168-192.

Sternberg, R. J., Torff, B., and Grigorenko, E. L. (1998a). Teaching for successful intelligence raises school achievement. Phi Delta Kappan 79: 667-669.

Sternberg, R. J., Torff, B., and Grigorenko, E. L. (1998b). Teaching triarchically improves school achievement. J. Educ. Psychol. 90: 374-384.

Sternberg, R. J., and Turner, M. E. (1981). Components of syllogistic reasoning. Acta Psychol. 47: 245-265.

Sternberg, R. J., and Vroom, V. H. (2002). The person versus the situation in leadership. Leadership Quart. 13: 301-323.

Sternberg, R. J., and Wagner, R. K. (1993). The g-ocentric view of intelligence and job performance is wrong. Curr. Direct. Psychol. Sci. 2(1): 1-4.

Sternberg, R. J., Wagner, R. K., and Okagaki, L. (1993). Practical intelligence: The nature and role of tacit knowledge in work and at school. In Reese, H., and Puckett, J. (eds.), Advances in Lifespan Development, Lawrence Erlbaum Associates, Hillsdale, NJ, pp. 205227.

Sternberg, R. J., Wagner, R. K., Williams, W. M., and Horvath, J. A. (1995). Testing common sense. Am. Psychol. 50(11): 912-927.

Sternberg, R. J., and Williams, W. M. (1996). How to Develop Student Creativity, Association for Supervision and Curriculum Development, Alexandria, VA. 
Sternberg, R. J., and Williams, W. M. (2001). Educational Psychology, Allyn \& Bacon, Boston, MA.

Stogdill, R. M. (1948). Personal factors associated with leadership: A survey of the literature. J. Psychol. 25: 35-71.

Stogdill, R. M., and Coons, A. E. (1957). Leader Behavior: Its Description and Measurement, Bureau of Business Research, Ohio State University, Columbus, $\mathrm{OH}$.

Tetewsky, S. J., and Sternberg, R. J. (1986). Conceptual and lexical determinants of nonentrenched thinking. J. Memory Lang. 25: 202-225.

Tolstoy, L. (1994). War and Peace (Translated by C. Garnett), Modern Library, New York.

Tzuriel, D. (1995). Dynamic-Interactive Assessment: The Legacy of L. S. Vygotsky and Current Developments, Unpublished manuscript.

Vernon, P. E. (1971). The Structure of Human Abilities, Methuen, London.

Vygotsky, L. S. (1978). Mind in Society: The Development of Higher Psychological Processes, Harvard University Press, Cambridge, MA.

Vroom, V. H., and Jago, A. G. (1978). On the validity of the Vroom-Yetton model. J. Appl. Psychol. 63: 151-162.

Vroom, V. H., and Yetton, P. W. (1973). Leadership and Decision Making, University of Pittsburgh Press, Pittsburgh.

Wagner, R. K. (1987). Tacit knowledge in everyday intelligent behavior. J. Person. Soc. Psychol. 52(6): 1236-1247.

Wagner, R. K., and Sternberg, R. J. (1986). Tacit knowledge and intelligence in the everyday world. In Sternberg, R. J., and Wagner, R. K. (eds.), Practical Intelligence: Nature and Origins of Competence in the Everyday World, Cambridge University Press, New York, pp. 51-83.

Ward, T. B. (1994). Structured imagination: The role of conceptual structure in exemplar generation. Cogn. Psychol. 27: 1-40.

Ward, T. B., Smith, S. M., and Finke, R. A. (1999). Creative cognition. In Sternberg, R. J. (ed.), Handbook of Creativity, Cambridge University Press, New York, pp. 189-212.

Weisberg, R. W. (1986). Creativity, Genius and Other Myths, Freeman, New York.

Weisberg, R. W. (1993). Creativity: Beyond the Myth of Genius, Freeman, New York.

Williams, W. M., Blythe, T., White, N., Li, J., Sternberg, R. J., and Gardner, H. I. (1996). Practical Intelligence for School: A Handbook for Teachers of Grades 5-8, HarperCollins, New York.

Williams, W. M., Blythe, T., White, N., Li, J., Gardner, H., and Sternberg, R. J. (2002). Practical intelligence for school: Developing metacognitive sources of achievement in adolescence. Dev. Rev. 22(2): 162-210.

Williams, W. M., and Sternberg, R. J. (1988). Group intelligence: Why some groups are better than others. Intelligence 12: 351-377.

Yukl, G. (1994). Leadership in Organizations, 3rd edn., Prentice-Hall, Englewood Cliffs, NJ.

Zaccaro, S. J., Kemp, C., and Bader, P. (2004). Leader traits and attributes. In Antonakis, J., Cianciolo, A. T., and Sternberg, R. J. (eds.), The Nature of Leadership, Sage, Thousand Oaks, CA, pp. 101-124.

Zimbardo, P. (1972). Pathology of imprisonment. Society 9(6): 4-8. 
Copyright of Educational Psychology Review is the property of Springer Science \& Business Media B.V.. The copyright in an individual article may be maintained by the author in certain cases. Content may not be copied or emailed to multiple sites or posted to a listserv without the copyright holder's express written permission. However, users may print, download, or email articles for individual use. 